Received: 16 May 2017

Accepted: 3 October 2017

Published online: 02 November 2017

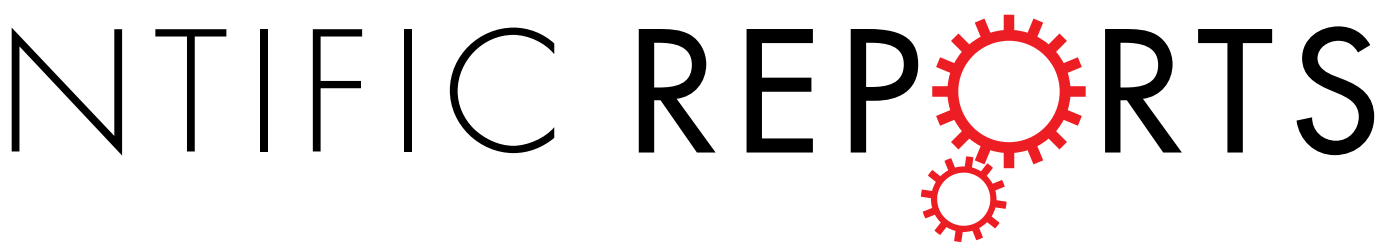

\title{
OPEN An impending inhibitor useful for the oil and gas production industry: Weight loss, electrochemical, surface and quantum chemical calculation
}

\begin{abstract}
Ambrish Singh ${ }^{1,2}$, K. R. Ansari ${ }^{3}$, Xihua Xu ${ }^{1}$, Zhipeng Sun ${ }^{1}$, Ashok Kumar ${ }^{4}$ \& Yuanhua Lin ${ }^{1,2}$
The influence of a Schiff base namely $\mathrm{N}, \mathrm{N}^{\prime}$-(pyridine-2,6-diyl)bis(1-(4-methoxyphenyl) methanimine) (PM) on the corrosion of $\mathrm{J} 55$ and $\mathrm{N} 80$ steel in $3.5 \mathrm{wt} . \% \mathrm{NaCl}$ solution saturated with $\mathrm{CO}_{2}$ was evaluated using weight loss, potentiodynamic polarization, electrochemical impedance spectroscopy (EIS), X-ray diffraction (XRD), contact angle, scanning electron microscopy (SEM), atomic force microscopy (AFM) and scanning electrochemical microscopy (SECM). Potentiodynamic polarization results suggested that the inhibitor acted as a mixed type inhibitor by reducing both anodic and cathodic reactions. The adsorption of PM on the J55 and N80 steel surface obeyed the Langmuir adsorption isotherm. XRD, contact angle, SEM, AFM and SECM studies revealed that the surface of the metal was quite unaffected after the addition of inhibitor. Quantum chemical calculations and molecular dynamic simulation support the experimental results well.
\end{abstract}

The varying amount of gases and the high concentration of salts in water are the major constituents of the oil and gas production industry ${ }^{1}$. Of the gases, carbon dioxide in the presence of high chloride concentrations is the most common corrosive medium in the petroleum industry, and such corrosion is said to be sweet $\operatorname{corrosion}^{2-4}$. Infrastructure such as pipe lines and oil well processing equipment in the oil and gas industry is made of carbon steel due to its lower cost. Although the carbon steel is resistant towards corrosion, in presence of a high content of chloride aqueous solutions of carbon dioxide, a significant corrosion problem arises. This corrosion problem results in a tremendous loss of the revenue to the oil and gas industry, either in the form of loss in production or repair costs for the production unit. Additionally, an indirect impact of corrosion occurs over the environment and ecology ${ }^{5}$.

The problems arising from carbon dioxide corrosion have lead to the development of various methods of corrosion control. Of these methods, injection of corrosion inhibitors has proven to be most practical and economic method due to its simplicity of use $\mathrm{e}^{6}$. Many organic compounds have been tested as corrosion inhibitors, but heteroatoms containing nitrogen, oxygen, and sulphur are the most commonly used inhibitors because the heteroatoms can easily interact with the metal surface by donating their lone electron pair. Hence, most of the organic compounds containing heteroatoms and multiple bonds act as good corrosion inhibitors ${ }^{7-9}$, and Schiff bases are the best known examples in this category. The review of the literature reveals that despite the superlative inhibition characteristics of Schiff bases in general, this class of compound has so far not been exploited as a corrosion inhibitor for carbon dioxide ${ }^{10,11}$. By keeping our eyes on the losses due to corrosion and environmental safety, we have synthesized $\mathrm{N}, \mathrm{N}^{\prime}$-(pyridine-2,6-diyl)bis(1-(4-methoxyphenyl)-methanimine), which shows various types

\footnotetext{
${ }^{1}$ School of Materials Science and Engineering, Southwest Petroleum University, Chengdu, 610500, Sichuan, China. ${ }^{2}$ State Key Laboratory of Oil and Gas Reservoir Geology and Exploitation, Southwest Petroleum University, Chengdu, Sichuan, 610500, China. ${ }^{3}$ Department of Chemistry, Indian Institute of Technology, Banaras Hindu University, Varanasi, 221005, U.P., India. " Department of Chemistry and Biochemistry, Arizona State University, Tempe, Arizona, 85287-1604, United States of America. Correspondence and requests for materials should be addressed to A.S. (email: vishisingh4uall@gmail.com) orY.L. (email:yhlin28@163.com)
} 


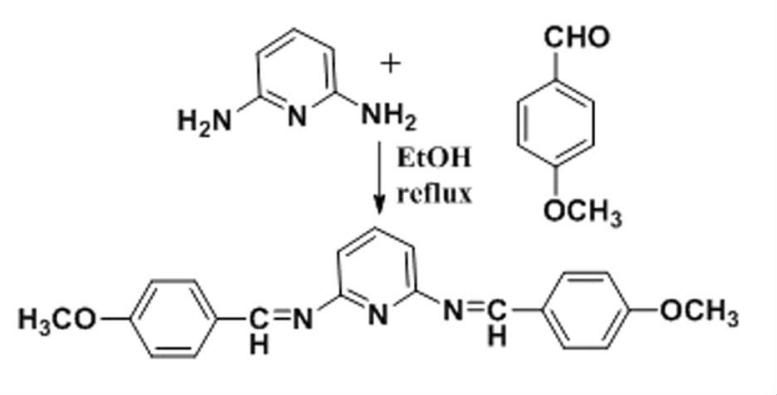

Figure 1. Synthetic scheme of inhibitors.

of biological activity such as antibacterial, antimicrobial, antitubercular, local anaesthetic, anti-inflammatory, anti-convulsant, anti-viral and anti-cancer ${ }^{12}$.

In the present study, $\mathrm{N}, \mathrm{N}^{\prime}$-(pyridine-2,6-diyl)bis(1-(4-methoxyphenyl)-methanimine) has been synthesized, and its corrosion inhibition effect was tested on both 555 and $\mathrm{N} 80$ steels in $3.5 \% \mathrm{NaCl}$ solution saturated with carbon dioxide using gravimetric methods, potentiodynamic polarization, electrochemical impedance spectroscopy (EIS), X-ray diffraction (XRD), UV-visible spectroscopy, contact angle measurement, scanning electron microscopy (SEM), atomic Force Microscopy (AFM), scanning electrochemical microscopy (SECM), quantum chemical calculations and molecular dynamic simulation (MD).

\section{Experimental procedures}

Inhibitor synthesis. 2,6-Diaminopyridine $(0.1 \mathrm{~mol})$ and 4-methoxybenzaldehyde $(0.2 \mathrm{~mol})$ were refluxed in ethanol $(20 \mathrm{~mL})$ for approximately $5 \mathrm{~h}$. The solid mass thus obtained was filtered and further recrystallized from ethanol $^{12}$. The synthesis scheme is shown in Fig. 1, and the ${ }^{1} \mathrm{H}-\mathrm{NMR}$, IR spectrum is given in supplementary file S1 and S2 respectively.

The detailed characterization is as follows:

$N, N^{\prime}$-(Pyridine-2,6-diyl) bis(1-(4-methoxyphenyl)-methanimine) (PM). ${ }^{1} \mathbf{H}-\mathrm{NMR}\left(500 \mathrm{MHz}, \mathrm{DMSO}-\mathrm{d}_{6}\right) \delta$ (ppm): 3.827 $\left(\mathrm{OCH}_{3}\right), 6.819-7.062(\mathrm{CH}$ Pyridine $) 7.802-7.819(\mathrm{CH}$ benzene $), 9.123(=\mathrm{CH})$.

IR $\left(\mathrm{KBr} \mathrm{cm}^{-1}\right): 3053(\mathrm{Ar}-\mathrm{CH}), 2875(\mathrm{C}-\mathrm{H}$ aliphatic $), 1715(\mathrm{C}=\mathrm{O}), 1617(\mathrm{C}=\mathrm{N}), 1580(\mathrm{C}=\mathrm{C})$.

N80 and J55 steel specimens. The composition of the steel samples is as follows: J55 steel (wt\%): C 0.24; Si 0.22; Mn 1.1; P 0.103; S 0.004; Cr 0.5; Ni 0.28; Mo 0.021; Cu 0.019; Fe remainder ${ }^{13}$ and N80 steel of (wt\%): C 0.31; Si 0.19; Mn 0.92; P 0.010; S 0.008; Cr 0.2; Fe remainder. The steel coupons are flat with a dimension of $5.0 \mathrm{~cm} \times 2.5 \mathrm{~cm} \times 0.2 \mathrm{~cm}$ and $2.0 \mathrm{~cm} \times 1.0 \mathrm{~cm} \times 0.025 \mathrm{~cm}$ used for gravimetric and electrochemical experiments, respectively. Only one end face $\left(1.0 \mathrm{~cm}^{2}\right)$ was exposed, and the rest was sealed by epoxy resin. All the steel coupons were abraded through 600, 800 and 1200 grit silicon carbide metallurgical paper, degreased in acetone, washed with anhydrous ethanol, and then dried at room temperature and finally kept in the desiccators ${ }^{14}$.

Experimental solution. In the present study, the test solution is $3.5 \% \mathrm{NaCl}$ saturated with carbon dioxide that was prepared by passing carbon dioxide gas through the solution for $120 \mathrm{~min}$ at a pressure of $6 \mathrm{MPa}$ until the $\mathrm{pH}$ of the solution became $4 \pm 0.05$ and, when necessary, the $\mathrm{pH}$ was adjusted with small amounts of NaHCO3 or $\mathrm{HCl}$. The $3.5 \% \mathrm{NaCl}$ solution was continuously saturated with $\mathrm{CO}_{2}$ throughout the experiment, and nitrogen gas was passed through the solution to minimize the oxygen concentration prior to each test. All the experiments were performed in static, unstirred solutions.

Weight loss experiments. The gravimetric experiments were done by immersing the steel samples (J55 and $\mathrm{N} 80)$ in $3.5 \% \mathrm{NaCl}$ solution saturated with $\mathrm{CO}_{2}$ for 7 days. The corrosion rate $\left(C_{\mathrm{R}}\right)$ and inhibition efficiency $(\eta \%)$ were calculated using the following equations:

$$
\begin{gathered}
\mathrm{C}_{\mathrm{R}}(\mathrm{mm} / \mathrm{y})=\frac{87.6 \mathrm{~W}}{\mathrm{atD}} \\
\eta \%=\frac{C_{\mathrm{R}}-C_{\mathrm{R}(\mathrm{i})}}{C_{\mathrm{R}}} \times 100
\end{gathered}
$$

where $W$ is the weight loss of the specimen $(\mathrm{mg}), a$ is the area of the specimen $\left(\mathrm{cm}^{2}\right), t$ represents the immersion time $(h)$, and $C_{\mathrm{R}}$ and $C_{\mathrm{R}(\mathrm{i})}$ are the corrosion rates in the absence and presence of the inhibitor molecules, respectively.

Electrochemical methods. All electrochemical studies, i.e., potentiodynamic polarization and electrochemical impedance spectroscopy (EIS) experiments were performed using a standard three electrode cell, which consists of J55 and N80 steel strips as working electrodes, a graphite rod as the counter electrode and $\mathrm{Ag} / \mathrm{AgCl}$ 

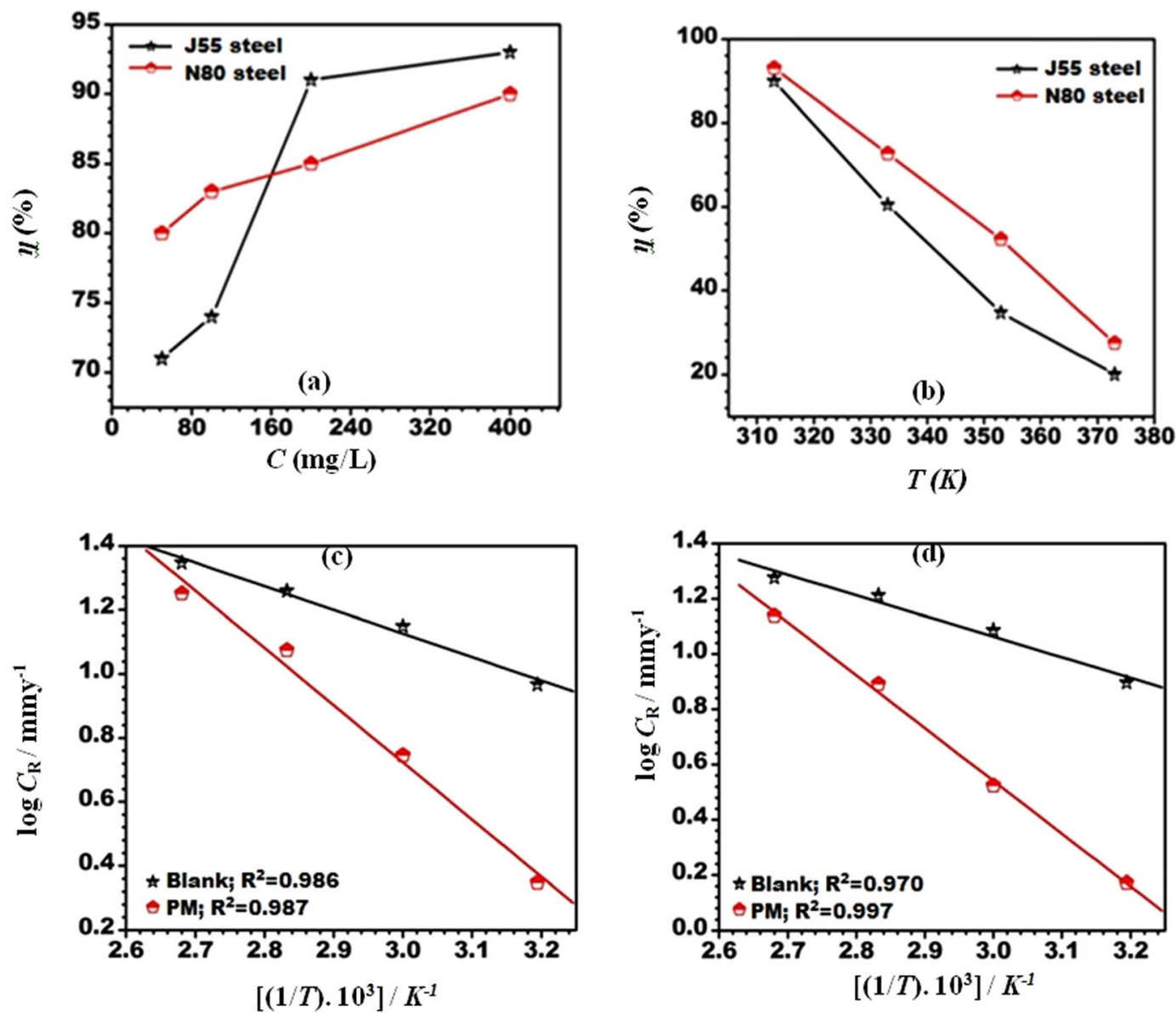

Figure 2. (a) Variation of inhibition efficiency ( $\eta \%)$ with inhibitor concentration at $313 \mathrm{~K}$. (b) Variation of inhibition efficiency $(\eta \%)$ with temperature. (c,d) Arrhenius plots of the corrosion rate $\left(C_{\mathrm{R}}\right)$ of $(\mathbf{c}) \mathrm{J} 55$ steel $(\mathbf{d})$ $\mathrm{N} 80$ steel in the absence and the presence of an optimum concentration of inhibitor.

as the reference electrode. The stable value for the open circuit potential was achieved by immersing the working electrodes in the test solution for $30 \mathrm{~min}$. Potentiodynamic polarization and EIS measurements were performed using the Autolab Potentiostat/Galvanostat electrochemical analysis device. EIS measurements were carried out in the frequency range of $100 \mathrm{kHz}$ to $0.00001 \mathrm{kHz}$ at the amplitude of $10 \mathrm{mV}$, peak to peak.

Potentiodynamic polarization was carried out by changing the potential from- $250 \mathrm{mV}$ to $+250 \mathrm{mV}$ vs open circuit potential (OCP) at a constant sweep rate of $1 \mathrm{mV} / \mathrm{s}$.

Surface analysis (SEM, AFM and XRD). Surface analysis of steel samples in the absence and presence of inhibitor was performed using the TESCAN VEGA II XMH instrument and AFM studies were performed using the NT-MDT SOLVER Next AFM/STM instrument. The scanned size of each sample used in AFM is $10 \mu \mathrm{m} \times 10 \mu \mathrm{m}$.

The films formed on the surface of the steel specimens were analysed using an X-ray diffractometer, X Pert PRO incorporated with High Score software.

Contact angle and SECM measurements. Contact angle measurements were performed using the sessile drop technique with the help of the DSA100 Kruss instrument made in Germany. SECM studies were carried out using an electrochemical work station of CHI900C model consisting of a three-electrode assembly.

Computational methods. Density Functional Theory (DFT) calculations are an important tool to predict the reactivity or stability of inhibitor molecules and were performed using the Gaussian 09 program ${ }^{15}$. Gauss View 5.0.8 was used to prepare the input files of inhibitor molecules ${ }^{16}$. The optimization of the inhibitor molecules was done using a 6-31 G (d, p) basis set. All the calculations have been carried for the aqueous phase, both for neutral and protonated inhibitor molecules. Quantum chemical parameters such as energy of the highest occupied molecular orbital $\left(E_{\mathrm{HOMO}}\right)$, energy of the lowest unoccupied molecular orbital $\left(E_{\mathrm{LUMO}}\right)$, electronegativity $(\chi)$, hardness $(\eta)$, softness $(\sigma)$ and the fraction of electrons transferred $(\Delta N)$ were calculated and discussed.

The ionization potential $(I P)$ and electron affinity $(E A)$ energies are correlated with the HOMO and LUMO of the inhibitor molecules, respectively, and can be expressed as follows ${ }^{17-20}$ : 

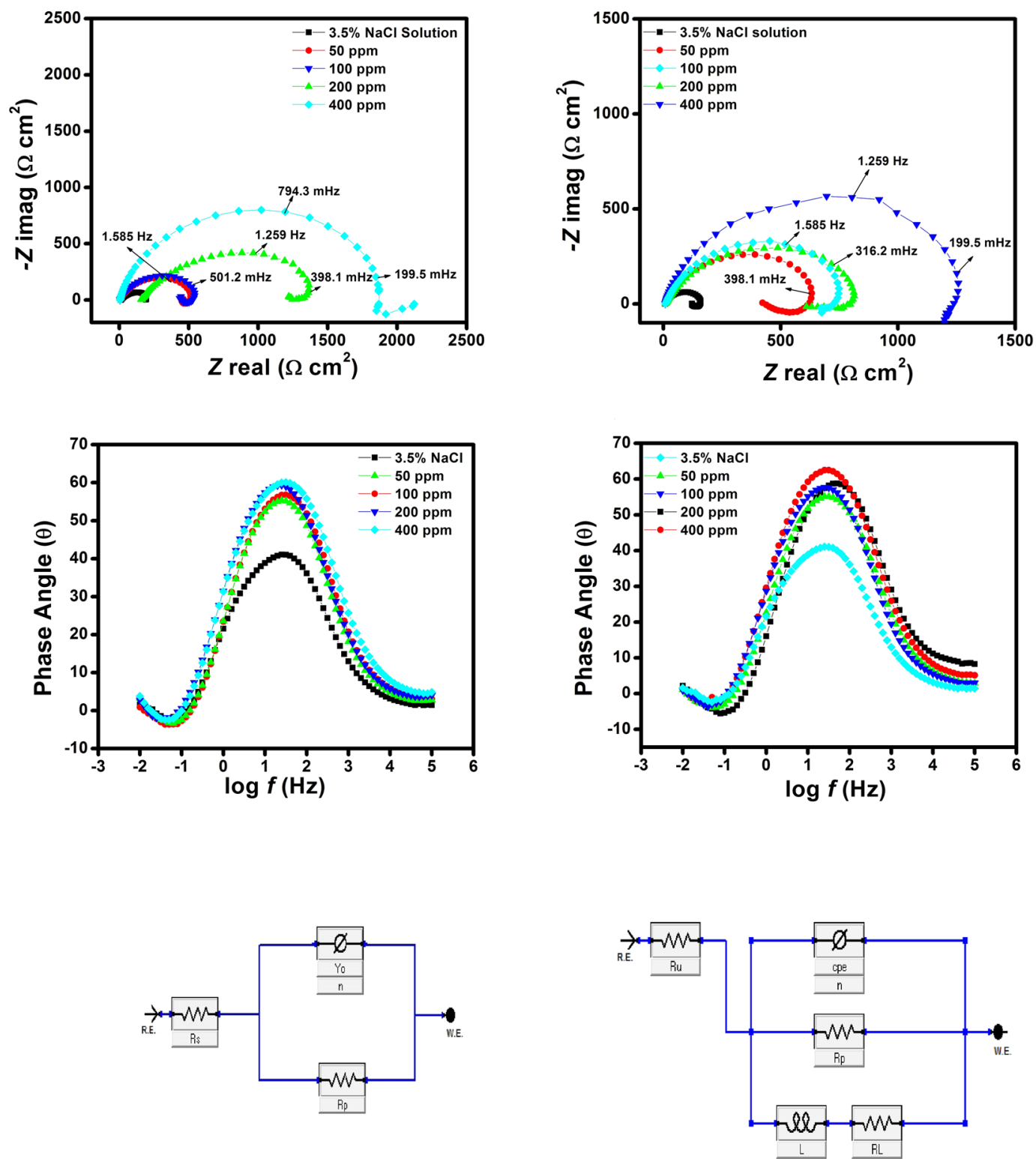

Figure 3. (a,b) Nyquist plots for (a) $\mathrm{J} 55$ steel (b) $\mathrm{N} 80$ steel in $3.5 \% \mathrm{NaCl}$ saturated with $\mathrm{CO}_{2}$ in absence and presence of different concentration of inhibitors at $313 \mathrm{~K}$. (c,d) Phase angle $\left(\log f\right.$ vs. $\left.\alpha^{\circ}\right)$ plots of impedance spectra for (c) $\mathrm{J} 55$ steel (d) $\mathrm{N} 80$ steel in $3.5 \% \mathrm{NaCl}$ saturated with $\mathrm{CO}_{2}$ in the absence and the presence of different concentrations of the inhibitors at $313 \mathrm{~K}$. (e,f) Equivalent circuit model used to fit the EIS data.

$$
\begin{gathered}
I P=-E_{\text {HOMO }} \\
E A=-E_{\text {LUMO }}
\end{gathered}
$$

Additionally, electronegativity $(\chi)$, global hardness $(\eta)$ and global softness $(\sigma)$ are given as follows ${ }^{21}$.

$$
\begin{gathered}
\chi=-\frac{1}{2}\left(E_{\text {HOMO }}+E_{L U M O}\right) \\
\eta=-\frac{1}{2}\left(E_{\text {HOMO }}-E_{L U M O}\right) \\
\sigma=\frac{1}{\eta}
\end{gathered}
$$



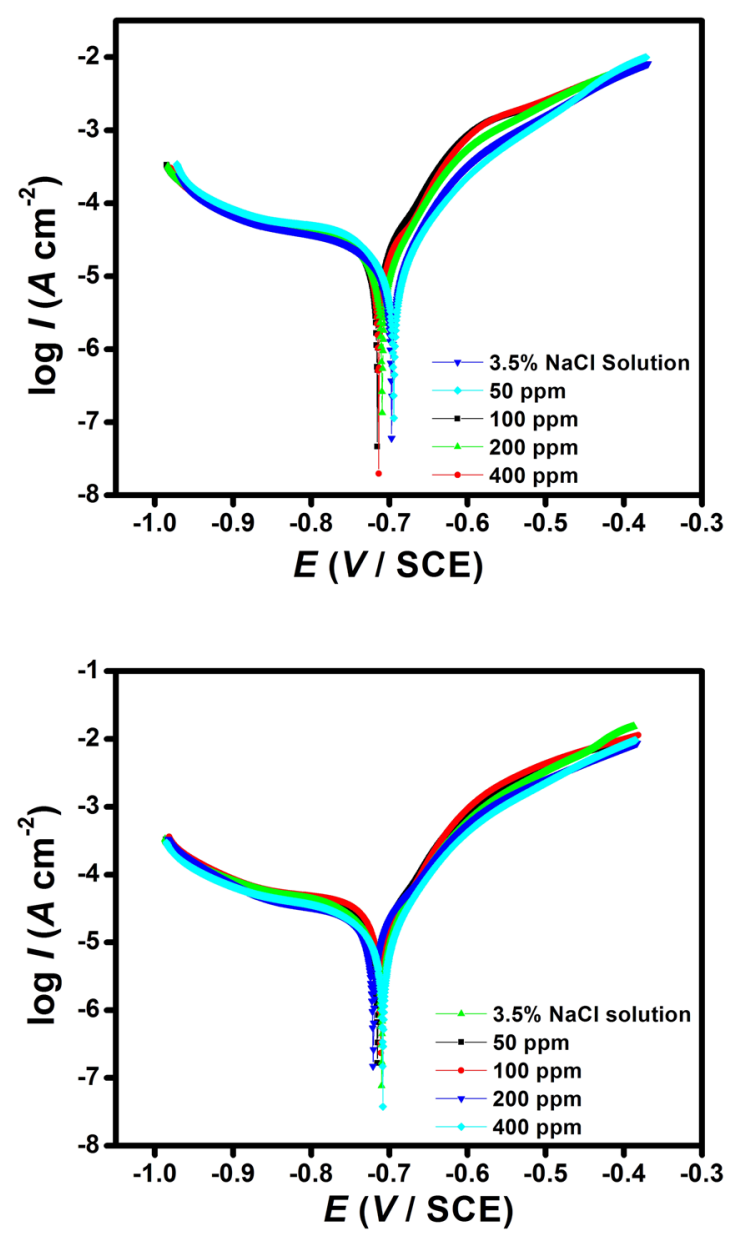

Figure 4. Potentiodynamic polarization curves for (a) J55 steel and (b) N80 steel in $3.5 \% \mathrm{NaCl}$ saturated with $\mathrm{CO}_{2}$ in the absence and the presence of different concentration of inhibitors at $313 \mathrm{~K}$.

The fraction of electrons transferred $(\Delta N)$ from the inhibitor molecules to the metal surface was calculated using the values of $\chi$ (electronegativity) and $\eta$ (global hardness) and can be expressed as follows ${ }^{22}$.

$$
\Delta N=\frac{\phi-\chi_{\mathrm{inh}}}{2\left(\eta_{\mathrm{Fe}}+\eta_{\mathrm{inh}}\right)}
$$

where $\phi$ is the work function and $\chi_{\mathrm{inh}}$ is the electronegativity of inhibitor molecule, $\eta_{\mathrm{Fe}}$ and $\eta_{\mathrm{inh}}$ denote the absolute hardness of iron and the inhibitor molecule. The values of $\phi$ and $\eta_{\mathrm{Fe}}$ are taken as 4.82 and $0 \mathrm{eV} \mathrm{mol}^{-123}$.

Molecular dynamics simulation. The interaction between the inhibitor molecules and the metal surface was studied using molecular dynamics (MD) simulations using the Forcite module of the Materials Studio 6.0 program developed by Accelrys, Inc. ${ }^{24,25}$. In this method, the most densely packed and stable iron surface was chosen, i.e., Fe-(110) for the adsorption study ${ }^{26}$. The MD simulation was performed at the temperature of $313 \mathrm{~K}$, controlled by the Andersen thermostat and NVT ensemble, with a time step of $1.0 \mathrm{fs}$ and simulation time of 100 0 ps, using the COMPASS ${ }^{27}$ force field.

Fukui functions. The calculation of the Fukui functions was performed using UCA-FUKUI v 1.0 software ${ }^{28}$ using the Finite Difference (FD) method with the help of the output file from Gaussian 09. The Fukui function $\left(f_{\mathrm{k}}\right)$ is the first derivative of the electronic density $\rho(\vec{r})$ with respect to the number of electrons $\mathrm{N}$, in a constant external potential $\mathcal{V}(\vec{r})$ and is written as follows ${ }^{29}$.

$$
f_{k}=\left(\frac{\partial \rho(\vec{r})}{\partial N}\right)_{\mathcal{V}(\vec{r})}
$$

Nucleophilic and electrophilic attacks were calculated using the Finite Difference approximations method ${ }^{29}$ :

$$
f_{k}^{+}=q_{k}(N+1)-q_{k}(N) \quad \text { (for nucleophilic attack) }
$$




\begin{tabular}{|c|c|c|c|c|c|c|c|c|}
\hline$C_{\text {inh }}$ & $R_{\mathrm{s}}$ & $R_{\mathrm{p}}$ & & $Y_{0}$ & $L$ & $R_{\mathrm{L}}$ & $\eta$ & \\
\hline$\left(\mathrm{mgL}^{-1}\right)$ & $(\Omega)$ & $\left(\Omega \mathrm{cm}^{2}\right)$ & $n$ & $\left(\mu \mathrm{F} / \mathrm{cm}^{2}\right)$ & $\left(\mathrm{H} \mathrm{cm}^{2}\right)$ & $\left(\Omega \mathrm{cm}^{2}\right)$ & $(\%)$ & $x^{2}$ \\
\hline \multicolumn{9}{|l|}{ J55 steel } \\
\hline Blank & 9.1 & 132 & 0.783 & 303 & - & - & - & $0.78 \times 10^{-2}$ \\
\hline 50 & 7.9 & 453 & 0.789 & 262 & 164 & 74 & 69 & $1.3 \times 10^{-2}$ \\
\hline 100 & 8.6 & 518 & 0.798 & 170 & 210 & 75 & 73 & $1.8 \times 10^{-2}$ \\
\hline 200 & 7.1 & 1421 & 0.833 & 95 & 285 & 92 & 90 & $1.2 \times 10^{-2}$ \\
\hline 400 & 8.1 & 1848 & 0.834 & 77 & - & - & 92 & $0.87 \times 10^{-2}$ \\
\hline \multicolumn{9}{|l|}{ N80 steel } \\
\hline Blank & 9.6 & 125 & 0.749 & 299 & 80 & 33 & - & $0.71 \times 10^{-2}$ \\
\hline 50 & 7.1 & 690 & 0.787 & 208 & 289 & 135 & 80 & $0.69 \times 10^{-2}$ \\
\hline 100 & 7.7 & 810 & 0.791 & 150 & 349 & 184 & 83 & $1.4 \times 10^{-2}$ \\
\hline 200 & 9.1 & 852 & 0.795 & 85 & 591 & 304 & 84 & $1.6 \times 10^{-2}$ \\
\hline 400 & 7.5 & 1301 & 0.801 & 67 & - & - & 90 & $0.54 \times 10^{-2}$ \\
\hline
\end{tabular}

Table 1. Electrochemical impedance parameters for $\mathrm{J} 55$ and $\mathrm{N} 80$ steel in $3.5 \% \mathrm{NaCl}$ saturated with $\mathrm{CO}_{2}$ in the absence and the presence of different concentrations of inhibitor at $313 \mathrm{~K}$.

$$
f_{k}^{-}=q_{k}(N)-q_{k}(N-1) \quad(\text { for electrophilic attack) }
$$

Here, $q_{\mathrm{k}}$ represents the gross charge of the atom. The charges on the anionic, neutral and cationic species are denoted by $q_{\mathrm{k}}(N+1), q_{\mathrm{k}}(N)$ and $q_{\mathrm{k}}(N-1)$ respectively.

\section{Results and Discussion}

Weight loss. Consequence of concentration. The percentage inhibition efficiency with the increase in inhibitor concentration is shown in Fig. 2a, which shows that the inhibition efficiency increases as the inhibitor concentration increases, suggesting that a greater number of inhibitor molecules is adsorbing over the active sites of the metal and thus preventing the direct contact between the metal and the aggressive solution. The highest inhibition efficiency obtained at $400 \mathrm{mg} / \mathrm{L}$ is $93 \%$ (J55 steel) and 90\% (N80 steel). However, a further increase in the inhibitor concentration provides no significant change in the value of the inhibition efficiency. Therefore, $400 \mathrm{mg} / \mathrm{L}$ has been selected to be the optimum concentration.

Consequence of temperature. The variation in the inhibition efficiency with increase in the temperature from 313 to $373 \mathrm{~K}$ at the optimum inhibitor concentration is shown in Fig. $2 \mathrm{~b}$. Figure $2 \mathrm{~b}$ shows that the inhibition efficiency decreased with the increase in the temperature for both J55 and N80 steels due to desorption of the inhibitor molecules from the metal surfaces ${ }^{30}$.

The activation energy for the corrosion process was calculated using the Arrhenius equation:

$$
\log C_{R}=\frac{-E_{a}}{2.303 R T}+\log \lambda
$$

where $E_{\mathrm{a}}$ represents the activation energy, $R$ is the universal gas constant, and $\lambda$ denotes the pre-exponential factor. The value of the activation energy in the absence and presence of the inhibitor was calculated by taking the linear regression between $\log C_{\mathrm{R}}$ and $1 / \mathrm{T}$ (Fig. 2c,d). The activation energy for both inhibited systems is higher than the activation energy for the uninhibited system, i.e., $14.46 \mathrm{~kJ} / \mathrm{mol}$ (uninhibited J55 steel), $14.07 \mathrm{~kJ} /$ $\mathrm{mol}$ (uninhibited N80 steel). However, in the presence of inhibitor, $E_{\mathrm{a}}$ increased to $36.59 \mathrm{~kJ} / \mathrm{mol}$ and $22.57 \mathrm{~kJ} / \mathrm{mol}$ for 555 and N80 steel, respectively.

The high values of $E_{\mathrm{a}}$ suggest that a high energy barrier has formed in presence of inhibitor for corrosion reactions. Thus, charging or mass transfer from the metal surface is avoided due to the adsorbed inhibitor molecules.

Electrochemical measurements. Electrochemical impedance spectroscopy (EIS). Impedance spectra for J55 and $\mathrm{N} 80$ steel in 3.5\% NaCl solution saturated with $\mathrm{CO}_{2}$ in the absence and presence of different concentrations of PM are shown in Fig. 3a-d in the form of Nyquist plots and Bode phase angle plots ${ }^{31}$. The Nyquist plots consist of depressed semicircles with one capacitive loop in the high frequency (HF) zone and one inductive loop in the lower frequency (LF) zone. The occurrence of an inductive loop is due to the relaxation process of $H_{\text {ads }}$ or $\mathrm{FeOH}_{\mathrm{ads}}{ }^{32}$. The diameter of the semicircle is increased with an increase in the inhibitor concentration, due to the adsorption of inhibitors forming a protective inhibitor film over the metal surface (Fig. 3a,b). The calculated EIS parameters from the Nyquist plots are given in Table 1.

The impedance results of the EIS spectra were calculated by fitting the two equivalent circuits (Fig. 3e,f), which consist of $R_{\mathrm{s}}$ (solution resistance), $R_{p}$ (polarization resistance), CPE (constant phase element) and $R_{\mathrm{L}}$ (inductive resistance) and $L$ (inductance) ${ }^{33}$. The presence of $L$ in the impedance spectra in the presence of the inhibitors that were investigated indicated that iron was still dissolved by the direct charge transfer at the inhibitor adsorbed electrode surface ${ }^{34}$. The impedance of the constant phase element is given by the following equation: 

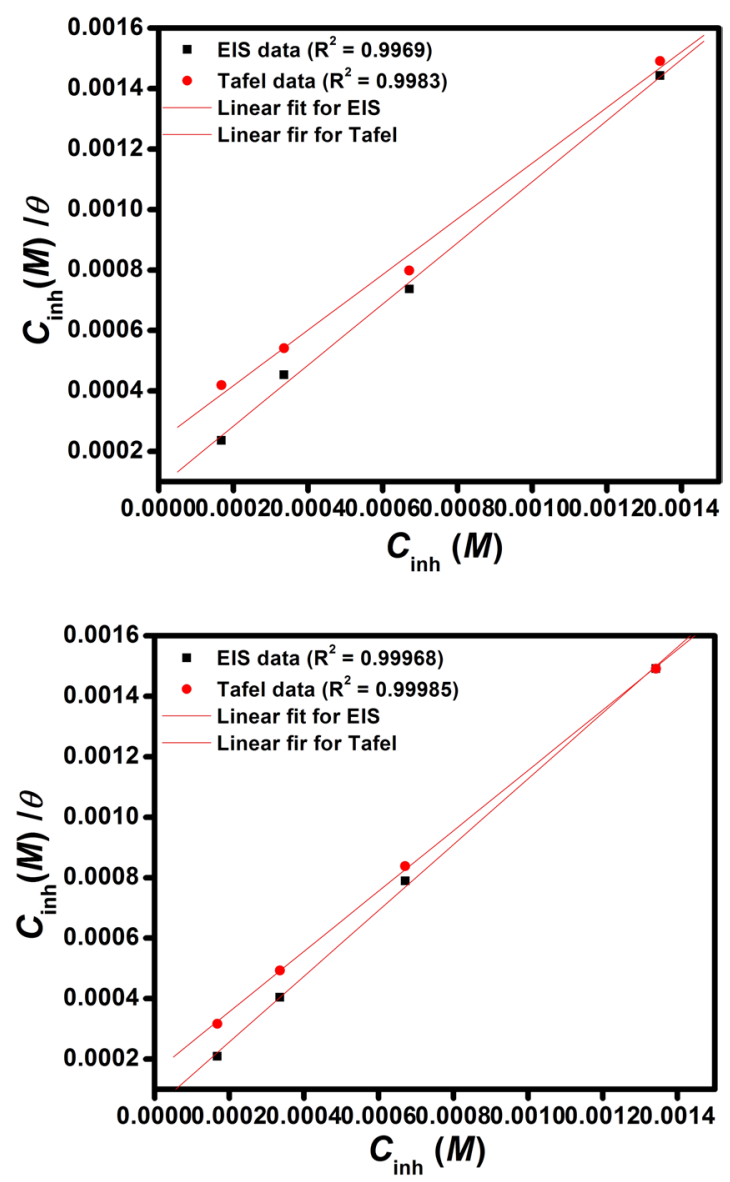

Figure 5. Langmuir adsorption isotherm plots for inhibitors (a) J55 steel and (b) N80 steel.

\begin{tabular}{|c|c|c|c|c|c|}
\hline$C_{\text {inh }}$ & $E_{\text {corr }}$ & $i_{\text {corr }}$ & $\beta_{\mathrm{a}}$ & $-\beta_{c}$ & $\eta$ \\
\hline$\left(\mathrm{mgL}^{-1}\right)$ & (mV/SCE) & $\left(\mu \mathrm{A} / \mathrm{cm}^{2}\right)$ & $(\mathrm{mV} / \mathrm{dec})$ & (mV/dec) & $(\%)$ \\
\hline \multicolumn{6}{|l|}{ J55 steel } \\
\hline Blank & -698 & 94.4 & 154 & 690 & - \\
\hline 50 & -697 & 57.1 & 118 & 436 & 40 \\
\hline 100 & -721 & 36.1 & 129 & 636 & 62 \\
\hline 200 & -709 & 15.3 & 113 & 758 & 84 \\
\hline 400 & -714 & 8.1 & 85 & 569 & 91 \\
\hline \multicolumn{6}{|l|}{ N80 steel } \\
\hline Blank & -715 & 106.3 & 129 & 179 & - \\
\hline 50 & -711 & 50.4 & 111 & 89 & 53 \\
\hline 100 & -722 & 34.1 & 97 & 113 & 68 \\
\hline 200 & -711 & 21.0 & 116 & 178 & 80 \\
\hline 400 & -724 & 10.2 & 114 & 102 & 90 \\
\hline
\end{tabular}

Table 2. Potentiodynamic polarization parameters for $\mathrm{J} 55$ and $\mathrm{N} 80$ steel in $3.5 \% \mathrm{NaCl}$ saturated with $\mathrm{CO}_{2}$ in the absence and the presence of different concentration inhibitor at $313 \mathrm{~K}$.

$$
Z_{C P E}=Y_{0}^{-1}(j \omega)^{-n}
$$

where $Y_{\mathrm{o}}$ is the magnitude of CPE, $j$ is the square root of -1 , and $n$ is the phase shift, which can be used as a gauge of the heterogeneity or roughness of the surface, and $\omega$ is the angular frequency ${ }^{35}$.

In EIS, degree of difficulty in corrosion reaction is reflected by $R_{\mathrm{p}}$ values, higher the value of $R_{\mathrm{p}}$ lower is the corrosion rate. Inspection of EIS data in Table 1 shows that $R_{\mathrm{p}}$ value increases with increasing the concentration of inhibitor. This reflects that the inhibitor prevents corrosion effectively and a protective layer on the electrode surface is formed. This layer acts as a barrier towards mass and charge transfer. The precision of the fitted data 

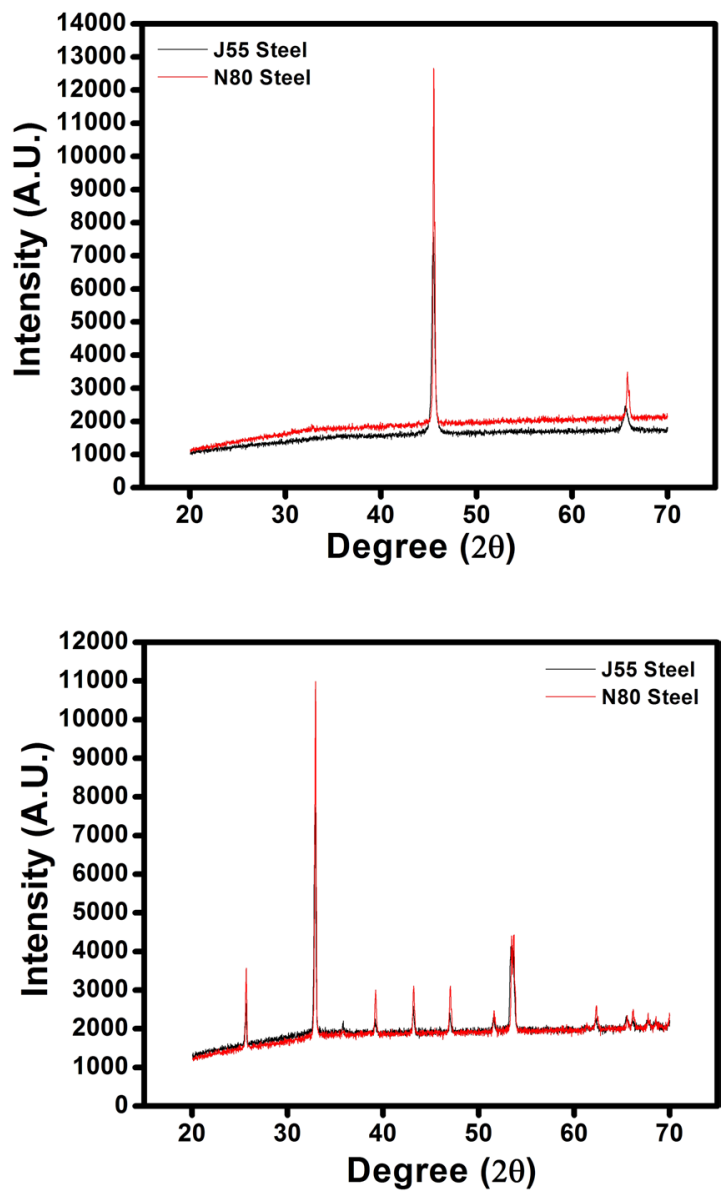

Figure 6. XRD spectra of (a) J55 sttel + N80 steel in Inhibited solution and (b) J55 steel + N80 steel in 3.5\% $\mathrm{NaCl}$ solution.

\begin{tabular}{|l|l|l|l|l|}
\hline \multirow{2}{*}{} & \multicolumn{2}{|l|}{ EIS } & \multicolumn{2}{l|}{ Tafel } \\
\cline { 2 - 5 } Inhibitor & $\boldsymbol{K}_{\text {ads }}$ & $-\Delta \mathbf{G}_{\text {ads }}^{\circ}$ & $\boldsymbol{K}_{\text {ads }}$ & $-\Delta \mathbf{G}_{\text {ads }}^{\circ}$ \\
\cline { 2 - 5 } & $\left(\mathbf{1 0}^{\mathbf{4}} \mathbf{M}^{-1}\right)$ & $\left(\mathbf{k J ~ m o l}^{-1}\right)$ & $\left(\mathbf{1 0}^{\mathbf{4}} \mathbf{M}^{-1}\right)$ & $\left(\mathbf{k J ~ m o l}^{-1}\right)$ \\
\hline Blank & - & - & - & - \\
\hline PM + J55 & 13.01 & 37.29 & 0.75 & 33.64 \\
\hline PM + N80 & 1.41 & 35.32 & 0.49 & 32.60 \\
\hline
\end{tabular}

Table 3. Thermodynamic parameters for the adsorption of inhibitor on $\mathrm{J} 55$ and $\mathrm{N} 80$ steel in $3.5 \% \mathrm{NaCl}$ saturated with $\mathrm{CO}_{2}$ in the absence and the presence of the optimum concentration of inhibitor.

was evaluated by chi-squared $\left(\chi^{2}\right)$. The values of $\chi^{2}$ are very small (Table 1 ), which supports that the equivalent circuit is ideal for fitting.

The inhibition efficiencies value can be calculated according to the following equation:

$$
: \eta \%=\left(1-\frac{R_{p}}{R_{p(i)}}\right) \times 100
$$

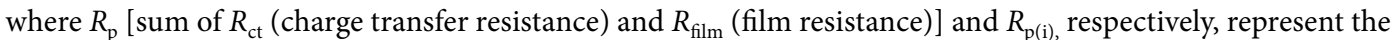
polarization resistance in the absence and the presence of different concentration of inhibitors. From the Table, we observe that the value of polarization resistance with the addition of inhibitors is increased, due to the formation of a protective film at the metal solution interface ${ }^{36}$. The decrease in the magnitude of CPE in presence of inhibitors (Table 1) indicates the increase in the thickness of the double layer. Additionally, the values of " $n$ " in presence of inhibitors increased from 0.787 to 0.834 compared to the blank 0.783 (J55 steel) and 0.749 (N80 steel), revealing that the metal surface becomes more homogeneous in the presence of inhibitor molecules ${ }^{37}$.

In the Bode phase angle plots (Fig. 3c,d), at the intermediate frequency the phase angle values obtained are in the range of $38.9^{\circ}$ to $-59.8^{\circ}$ for $\mathrm{J} 55$ steel and $39.1^{\circ}$ to $-61.2^{\circ}$ for N80 steel. However, an ideal capacitor phase 


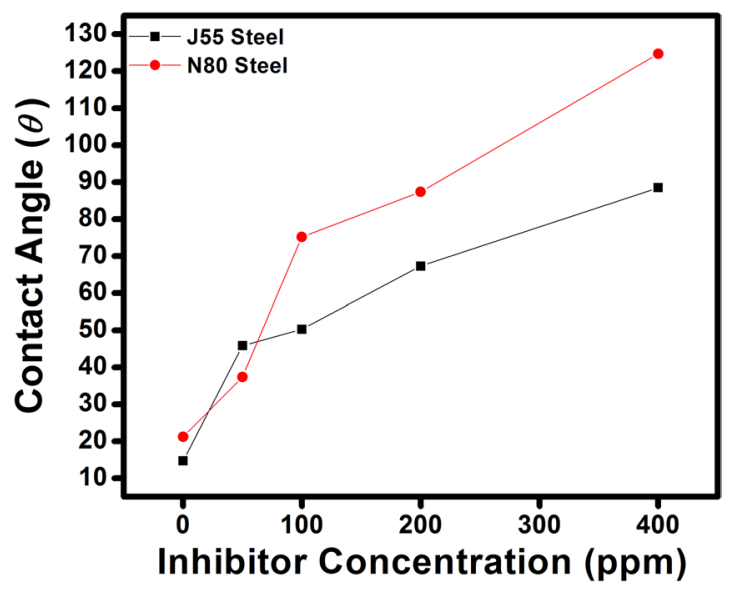

Figure 7. Contact angle versus inhibitor concentration plots for inhibitors.
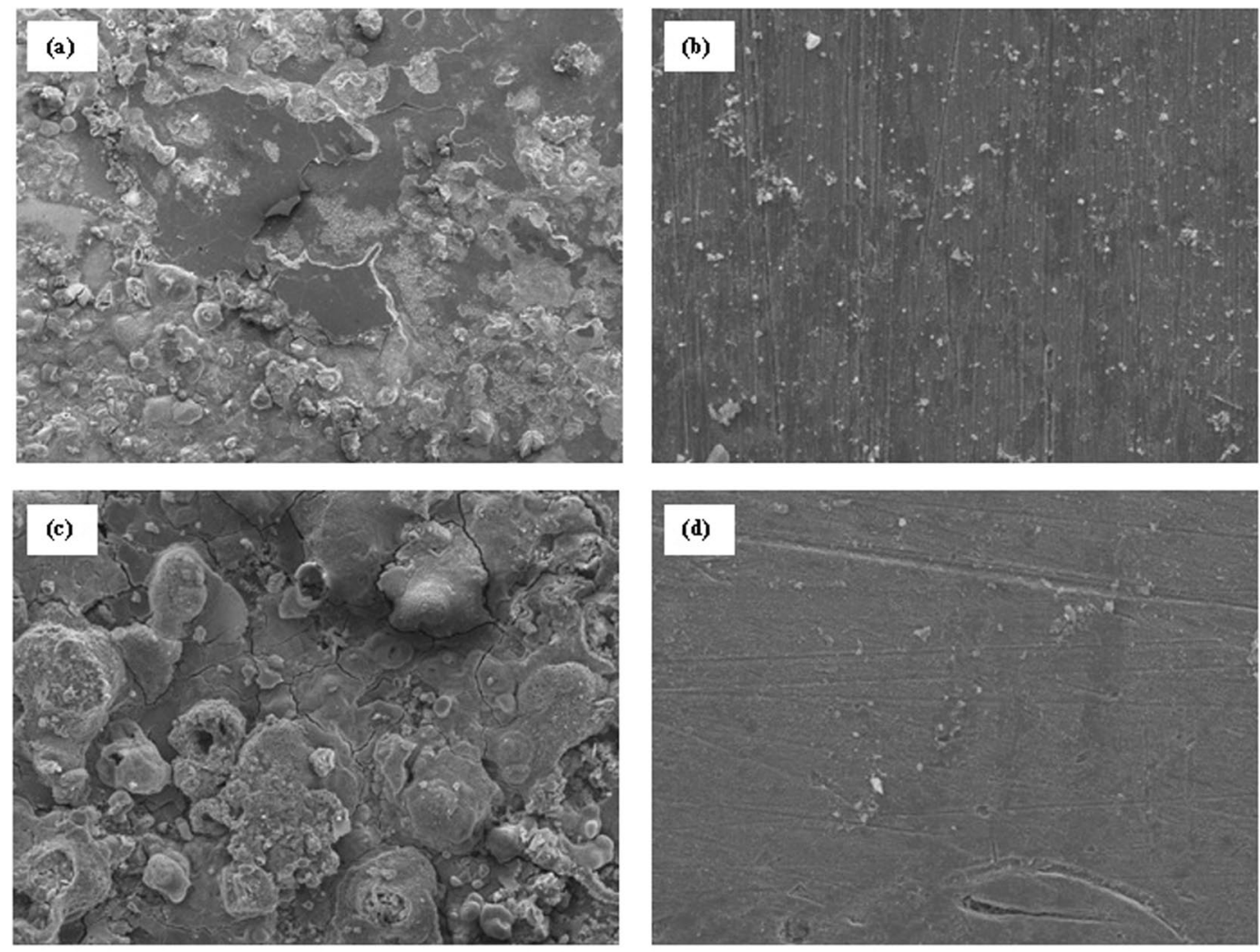

Figure 8. SEM images for (a) Blank J55 steel (b) PM+ J55 steel (c) Blank N80 steel (d) PM + N80 steel.

angle at an intermediate frequency is $-90^{\circ 38}$. Thus, the approach of the phase angle to $-90^{\circ}$ with the addition of inhibitors suggests that the electrochemical behaviour of corrosion becomes more capacitive ${ }^{39}$.

Potentiodynamic polarization. Potentiodynamic polarization curves for J55 and N80 steel in the absence and the presence of inhibitor in $3.5 \% \mathrm{NaCl}$ solution saturated with $\mathrm{CO}_{2}$ at $3131 \mathrm{~K}$ temperature are shown in Fig. 4a,b. The linear portion of the cathodic and anodic Tafel line allows the calculation of some valuable potentiodynamic parameters such as corrosion current density $\left(i_{\text {corr }}\right)$, corrosion potential $\left(E_{\text {corr }}\right)$, cathodic and anodic Tafel slopes $\left(b_{c}, b_{\mathrm{a}}\right)$ and inhibition efficiency $(\eta \%)$. These parameters are tabulated in Table $2^{40}$. The inhibition efficiency was calculated using the following equation: 

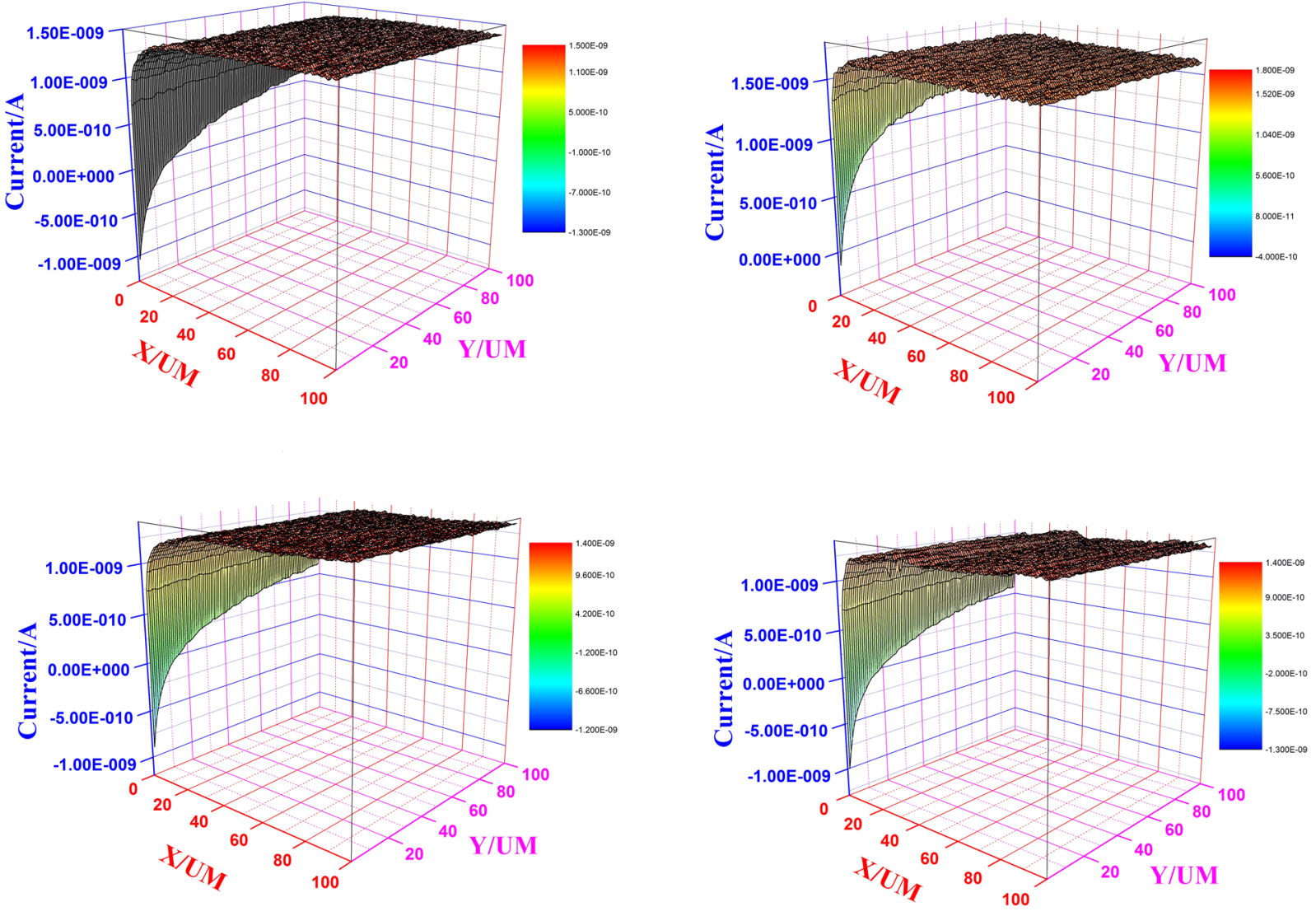

Figure 9. SECM figures for (a) Blank $y$-axis 3D-J55 steel (b) Blank $y$-axis 3D-N80 steel (c) PM + J55 steel $y$-axis 3D (c) $\mathrm{PM}+\mathrm{N} 80$ steel $y$-axis 3D.

$$
\eta \%=\left(1-\frac{i_{\text {corr }(\mathrm{i})}}{i_{\text {corr }}}\right) \times 100
$$

where $i_{\text {corr }}$ and $i_{\text {corr(i) }}$ are the corrosion current density in the absence and the presence of inhibitor, respectively. Table 2 shows that as the inhibitor concentration is increased, there is a significant reduction in the corrosion current densities occurring from $94.4 \mu \mathrm{A} \mathrm{cm}^{-2}$ to $9.1 \mu \mathrm{A} \mathrm{cm}^{-2}$ for J55 steel and from $106.3 \mu \mathrm{A} \mathrm{cm}^{-2}$ to $10.2 \mu \mathrm{A} \mathrm{cm} \mathrm{cm}^{-2}$ for $J 55$ steel, which reflects that the corrosion reactions are inhibited. The shifts in the $E_{\text {corr }}$ values show an almost constant trend, with a maximum change of $53 \mathrm{mV}$. Such types of $E_{\text {corr }}$ value change have been attributed to a mixed type of inhibitor action ${ }^{41,42}$. The anodic and cathodic Tafel slope values in the presence of inhibitor for both steels (J55 and N80) shows some variations (Table 2) compared to the values in the absence of inhibitor, suggesting that in the presence of inhibitor, both the anodic and cathodic corrosion reactions are affected. Additionally, with the increase in the inhibitor concentration the values of inhibition efficiency increase, due to the formation of an adsorbed film of inhibitor molecules over the metal surface.

Adsorption isotherm. In the current investigation various isotherms were tried such as Temkin, Frumkin and Langmuir. However, the Langmuir isotherm was the best fit. The Langmuir isotherm is expressed by the following equation ${ }^{43}$ :

$$
\frac{C_{i n h}}{\theta}=\frac{1}{K_{a d s}}+C_{i n h}
$$

where $K_{\mathrm{ads}}$ is the equilibrium adsorption constant, $C_{\mathrm{inh}}$ is the inhibitor concentration and $\theta$ is the fraction of the surface covered by inhibitor molecules. After plotting as a graph between $C_{\text {inh }} / \theta$ versus $C_{\text {inh }}$, a straight line was obtained (Fig. 5a,b), with a correlation coefficient $\left(R^{2}\right)$ for J55 steel ranging from 0.9969 for EIS and 0.9983 for Tafel polarization and N80 steel from 0.99968 for EIS and 0.99986 for Tafel polarization. Values of $K_{\text {ads }}$ represent the strength between adsorbate and adsorbent, i.e., larger values of $K_{\text {ads }}$ imply stronger adsorption and hence, better inhibition efficiency ${ }^{44-46}$. The equilibrium adsorption constant $\left(K_{\mathrm{ads}}\right)$ is related to the standard free energy of adsorption $\left(\Delta G_{\text {ads }}^{\circ}\right)$ through the following equation:

$$
\Delta G_{a d s}^{\circ}=-R T \ln \left(55.5 K_{a d s}\right)
$$




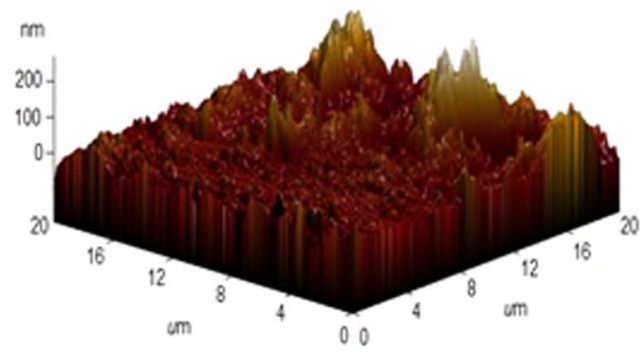

(a)

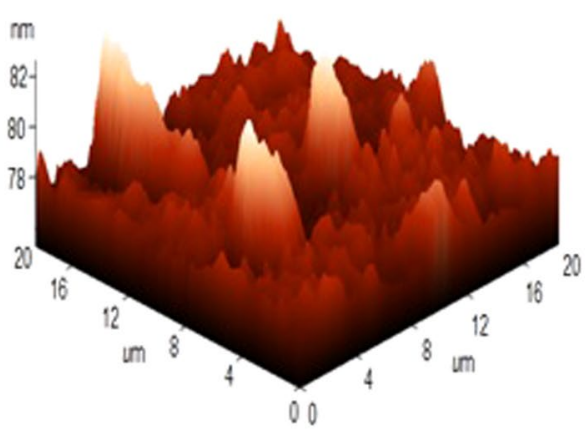

(c)

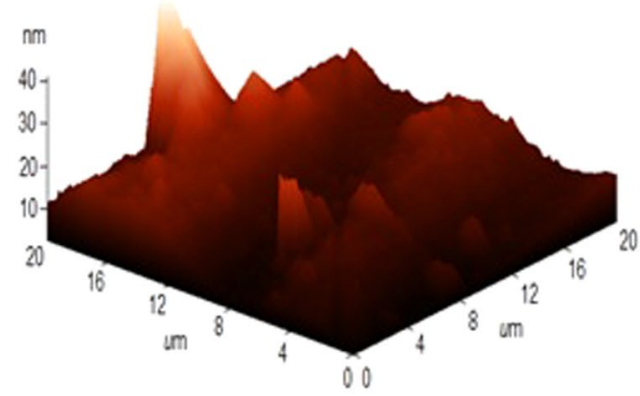

(b)

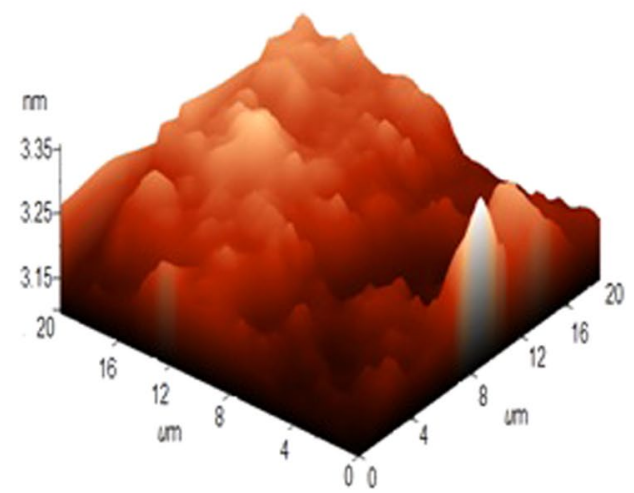

(d)

Figure 10. Atomic force microscopy images for (a) Blank-J55 steel (b) Blank-N80 steel (c) PM + J55 steel and (d) PM+ N80 steel.

\begin{tabular}{|l|l|l|l|l|l|}
\hline Inhibitors & $\boldsymbol{E}_{\text {Номо }}$ & $\boldsymbol{E}_{\text {LUмо }}$ & $\chi$ & $\eta$ & $\Delta \boldsymbol{N}$ \\
\hline $\mathrm{PM}$ & -5.440 & -1.577 & 3.508 & 1.931 & 0.339 \\
\hline $\mathrm{PM}^{+}$ & -8.540 & -5.616 & 7.078 & 1.462 & -0.772 \\
\hline
\end{tabular}

Table 4. Calculated quantum chemical parameters of the inhibitor. All energy values are in $\mathrm{eV}^{\mathrm{b}}{ }^{\mathrm{b}} \mathrm{\text {is }}$ in $\mathrm{eV}^{-1}$; $\mathrm{PM}^{+}$is the protonated inhibitor.

where, $R$ is the gas constant, and $T$ is the absolute temperature. The value of 55.5 is the concentration of water in the solution in $\mathrm{mol} \mathrm{L}^{-1}$. The values of $K_{\mathrm{ads}}$ and $\Delta G^{\circ}$ ads are given in Table 3 . The negative values of $\Delta G^{\circ}$ ads ensure the spontaneity of the adsorption process and the stability of the adsorbed film on the steel surface ${ }^{47}$. Generally, values of $\Delta G_{\text {ads }}^{\circ} \leq-20 \mathrm{~kJ} \mathrm{~mol}^{-1}$ signify physisorption, and values more negative than $-40 \mathrm{~kJ} \mathrm{~mol}^{-1}$ signify chemisorption. The calculated value of $\Delta G^{\circ}$ ads for 555 steel with inhibitor is in the range of $-37.29 \mathrm{~kJ} / \mathrm{mol}$ to $-33.64 \mathrm{~kJ} / \mathrm{mol}$ and for $\mathrm{N} 80$ steel with inhibitor is in the range of $-35.32 \mathrm{~kJ} / \mathrm{mol}$ to $-32.60 \mathrm{~kJ} / \mathrm{mol}$ (Table 3), which probably indicate that both physical and chemical adsorption would occur.

X-Ray Diffraction (XRD). The corrosion product over the surface of the carbon steel samples was determined by X-ray diffraction, and the results are shown in Fig. $6 a$,b. Peaks at $2 \theta=33^{\circ}, 40^{\circ}, 44^{\circ}, 48^{\circ}, 51^{\circ}, 52^{\circ}$, and $66^{\circ}$ can be assigned to the oxides of iron. The XRD patterns of the inhibited surface (Fig. $6 \mathrm{~b}$ ) show the presence of iron peaks only. The peaks due to oxides of iron are found to be absent ${ }^{48}$, attributed to the formation of a protective film of inhibitor over the metal surface.

Contact Angle. The contact angle measurement was carried out in the absence and presence of inhibitor both for J55 and N80 steel and is shown in Fig. 7. The contact angle in the absence of inhibitor for J55 steel was measured as $21.2^{\circ}$ and for N80 steel was $14.7^{\circ}$. In the absence of inhibitor, the value of the contact angle is lower, suggesting that the metal surface shows hydrophilic properties and favours water molecules to adsorb and cause more corrosion ${ }^{13}$. However, as the inhibitor is added, the contact angle values increased to $124.7^{\circ}$ for J55 steel and $88.5^{\circ}$ for N80 steel, supporting that metal surfaces became hydrophobic and repelled water molecules, and thus the corrosion process is reduced. This result confirms that the inhibitor molecules are adsorbed and make a film over the metal surface ${ }^{49}$. 


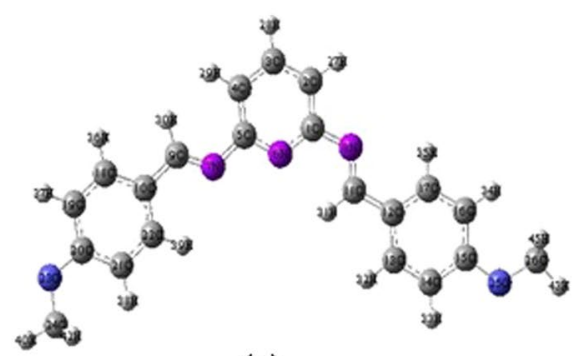

(a)

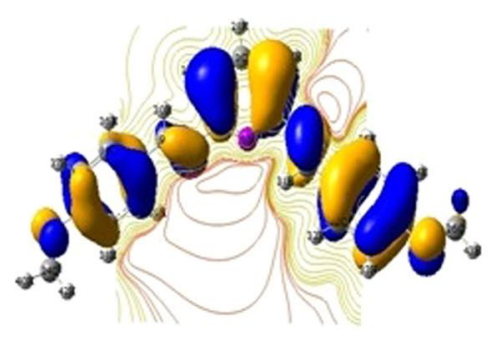

(c)

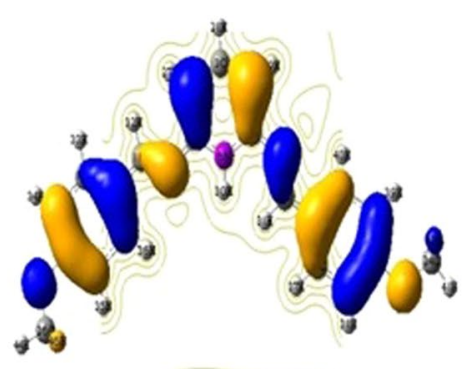

(e)

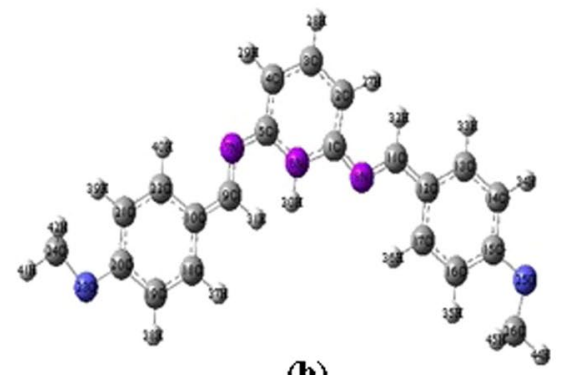

(b)

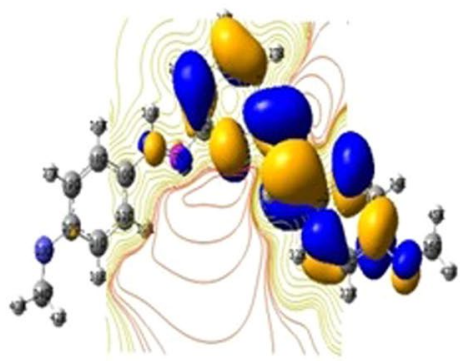

(d)

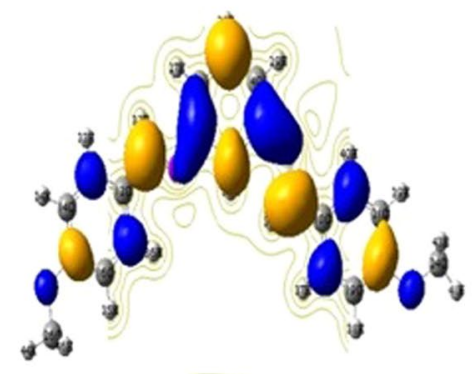

(f)

Figure 11. (a,b) Optimized geometries (a) neutral (b) protonated. (c,d) Frontier molecular orbitals of the neutral inhibitor (c) HOMO (d) LUMO. (e,f) Frontier molecular orbitals of the protonated inhibitor (c) HOMO (d) LUMO.

Surface analysis. Scanning Electron Microscopy (SEM). The SEM micrograph of J55 and N80 steels in the absence and presence of the optimum concentration of the inhibitor is shown in Fig. 8a-d. In the absence of inhibitor, the steel surfaces are rough due to the damage caused by the corrosive attack of the carbonic acid (Fig. 8a,b). However, in the presence of the inhibitor, the steel surfaces become $\operatorname{smooth}^{50}$ (Fig. 8c,d). This result further supports the presence of an adsorbed inhibitor film over the metal surface ${ }^{51}$.

Scanning Electrochemical Microscopy (SECM). Figure 9a-d shows the 3-D form of SECM images of J55 and N80 steel samples immersed in $3.5 \% \mathrm{NaCl}$ solution saturated with $\mathrm{CO}_{2}{ }^{52-55}$. In absence of inhibitor, when the tip of the probe was brought near to the metal surface, the current started to increase, suggesting the conductive nature of the metal surface (Fig. 9a,c) ${ }^{56}$. However, in the presence of the inhibitor when the probe is brought near to the metal surface, the value of the current decreases (Fig. 9b,d), suggesting that the metal surface becomes insulating due to the adsorbed inhibitor film ${ }^{57}$.

Atomic Force Microscopy (AFM). The 3-D AFM images of steel surfaces in the absence and presence of inhibitor are shown in Fig. 10a-d. In the absence of the inhibitor, the metal surface was damaged. The damage is strongly attributed to the dissolution of the oxide film and the maximum height scale reaching up to $200 \mathrm{~nm}$ and $82 \mathrm{~nm}$ for N80 and J55 steels respectively (Fig. 10a,b). However, in the presence of the inhibitor, the metal surface appears flatter, homogeneous 


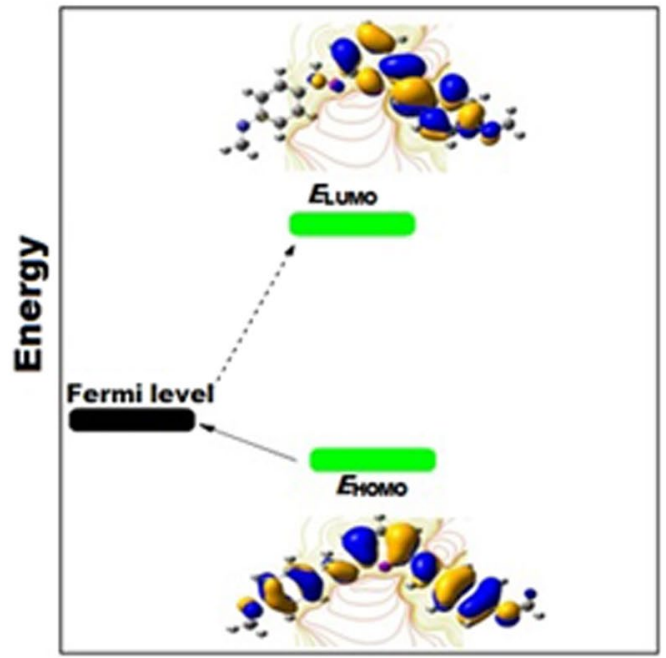

(a)

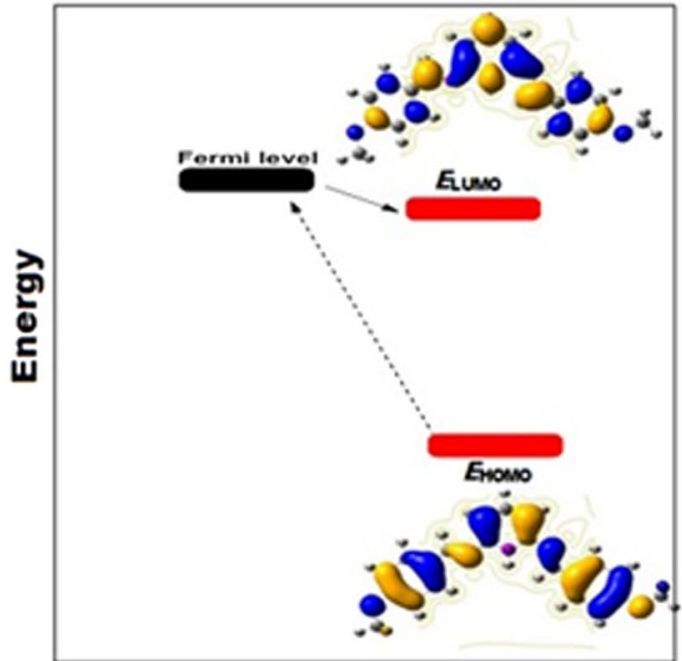

(b)

Figure 12. (a,b) Frontier orbital energetic positions of inhibitor molecule with iron surface (a) neutral inhibitor (b) protonated inhibitor.

\begin{tabular}{|l|l|l|}
\hline Atoms & $f_{k}{ }^{-}$ & $f_{k}{ }^{+}$ \\
\hline C1 & 0.0219 & 0.075 \\
\hline C2 & 0.1709 & 0.0115 \\
\hline C3 & -0.2410 & 0.0423 \\
\hline C4 & 0.1735 & 0.0789 \\
\hline C5 & 0.0226 & -0.0033 \\
\hline N6 & -0.0039 & 0.0654 \\
\hline N7 & 0.0591 & 0.0003 \\
\hline N8 & 0.0824 & 0.1057 \\
\hline C9 & 0.0067 & 0.0005 \\
\hline C10 & 0.0480 & 0.0001 \\
\hline C11 & 0.0123 & 0.2949 \\
\hline C12 & 0.0860 & 0.0166 \\
\hline C13 & 0.0066 & 0.0681 \\
\hline C14 & 0.0452 & -0.0067 \\
\hline C15 & 0.0523 & 0.1192 \\
\hline C16 & 0.0362 & -0.0089 \\
\hline C17 & 0.0150 & 0.1240 \\
\hline C18 & 0.0037 & 0.0000 \\
\hline C19 & 0.0253 & 0.0000 \\
\hline C20 & 0.0293 & 0.0001 \\
\hline C21 & 0.0204 & 0.0000 \\
\hline C22 & 0.0085 & 0.0001 \\
\hline O23 & 0.0389 & 0.0000 \\
\hline C24 & -0.0004 & 0.0000 \\
\hline O25 & 0.0693 & 0.0222 \\
\hline C26 & -0006 & -0001 \\
\hline & & \\
\hline
\end{tabular}

Table 5. Calculated Fukui functions for the studied inhibitor molecules in neutral form.

and uniform, and the maximum height scale decreases to $40 \mathrm{~nm}$ and $3.35 \mathrm{~nm}$ for N80 and J55 steels, respectively (Fig. 10b,d $)^{58}$. These results further support the formation of an inhibitor film over the metal surface.

Quantum chemical calculations. The optimized geometry and frontier orbital energy of neutral and protonated inhibitor are shown in Fig. 11a-f. The quantum chemical parameters are tabulated in Table 4. The adsorption of inhibitor molecules over the metal surface depends upon the position of the frontier orbital energy level between the inhibitor molecules and the Fermi level of the iron metal ${ }^{59}$.The frontier orbital energies of inhibitor 


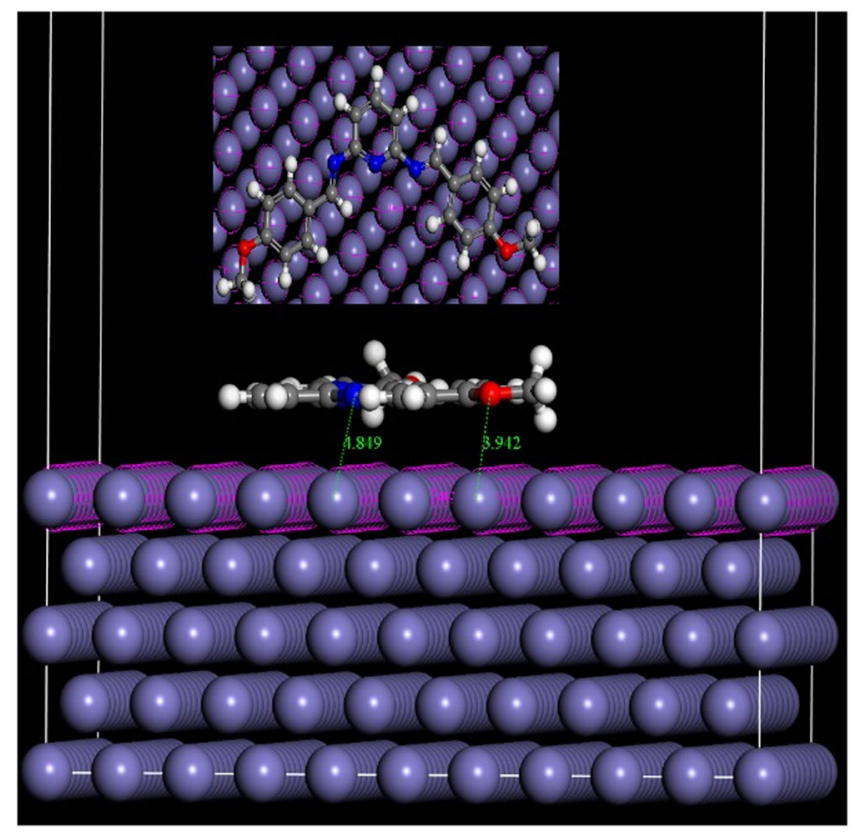

Figure 13. Top and side views of the most stable configurations for adsorption of inhibitor on Fe (110) surface calculated using Monte Carlo simulations.

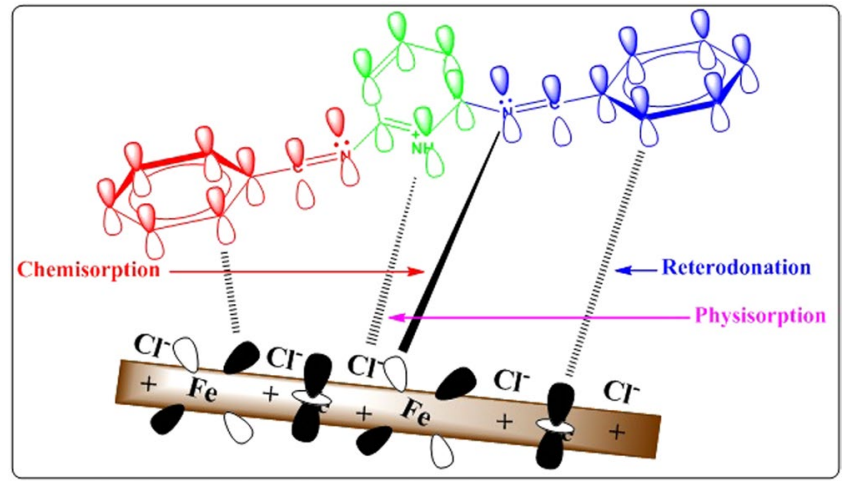

Figure 14. Mechanism of corrosion mitigation of steel in the presence of inhibitor in $3.5 \% \mathrm{NaCl}$ solution saturated with $\mathrm{CO}_{2}$.

molecules in neutral and protonated forms and the Fermi level of iron are shown in Fig. 12a,b. Figure 12a shows that in the neutral form of the inhibitor, the $E_{\mathrm{HOMO}}$ energy level is at $-5.440 \mathrm{eV}$, very close to the Fermi level of iron, i.e., $-5.177 \mathrm{eV}$. However, the $E_{\mathrm{LUMO}}$ energy level is at $-1.577 \mathrm{eV}$, far away from the Fermi level of iron. Therefore, the transfer of an electron from the HOMO energy level to the iron surface can easily take place. The energy gap between the Fermi level of iron and the $E_{\mathrm{LUMO}}$ of the inhibitor molecule is large. Thus, the transfer of an electron from the iron surface to the LUMO orbital of the inhibitor molecule is very difficult.

In the case of the protonated form of the inhibitor molecule (Fig. 12b), the Fermi level of iron $(-5.177 \mathrm{eV})$ is very close to the $E_{\mathrm{LUMO}}$ energy level $(-5.616 \mathrm{eV})$, while the $E_{\mathrm{HOMO}}$ energy level $(-8.540 \mathrm{eV})$ is far from the Fermi level of iron. Thus, it could be very difficult for the electron transfer from the HOMO orbital to the iron surface to occur. However, the electron transfer occurs from the iron surface to the LUMO energy level. Furthermore, Table 4 reveals that the calculated $\Delta N$ value in the neutral form is positive, suggesting that the electron-donating capacity of the inhibitor molecules, while in the protonated form, becomes negative, which indicate that inhibitor molecules cannot donate electrons rather than accepting electrons from the metal.

Fukui index analysis. Fukui index analysis was used to analyse the sites present over the inhibitor molecules, which are participating in the donor-acceptor interactions with the metal surface. The sites on the inhibitor molecules that donate and accept electrons are represented by $f_{\mathrm{k}}{ }^{-}$(nucleophilic site) and $f_{\mathrm{k}}{ }^{+}$(electrophilic site), respectively ${ }^{60}$. Thus, the higher the values of $f_{\mathrm{k}}{ }^{-}$and $f_{\mathrm{k}}{ }^{+}$, the greater would be the electron donation and acceptance tendency, respectively. The calculated Fukui indices are presented in Table 5. In the studied inhibitor $\mathrm{C}(1)$, $\mathrm{C}(2), \mathrm{C}(4), \mathrm{C}(5), \mathrm{N}(7), \mathrm{N}(8), \mathrm{C}(10), \mathrm{C}(11), \mathrm{C}(12), \mathrm{C}(14), \mathrm{C}(15), \mathrm{C}(16), \mathrm{C}(17), \mathrm{C}(19), \mathrm{C}(20), \mathrm{C}(21), \mathrm{O}(23)$ and 


\begin{tabular}{|l|l|l|l|l|}
\hline System & Total Energy & Adsorption Energy & Rigid Adsorption Energy & Deformation Energy \\
\hline Fe + PM & -30.208 & -111.010 & -8.716 & -102.294 \\
\hline
\end{tabular}

Table 6. Adsorption energies for inhibitor on Fe (110) surface obtained using the molecular dynamic simulation (in $\mathrm{kJ} / \mathrm{mol}$ ).

$\mathrm{O}(25)$ atoms are more susceptible sites for donation of electron and $\mathrm{C}(1), \mathrm{C}(2), \mathrm{C}(3), \mathrm{C}(4), \mathrm{N}(6), \mathrm{N}(8), \mathrm{C}(11)$, $\mathrm{C}(12), \mathrm{C}(13), \mathrm{C}(15), \mathrm{C}(17)$ and $\mathrm{O}(25)$, atoms are the most favourable sites for electron acceptance. Thus, heterocyclic rings along with the phenyl rings are most reactive sites for electron donor-acceptor interactions and facilitate inhibitor adsorption onto the steel surfaces.

Molecular dynamics simulations. The interaction between the metal and inhibitor was studied using molecular dynamics simulations, and the results are shown in Fig. 13. The parameters such as total energy, adsorption energy, rigid adsorption energy, and deformation energy are tabulated in Table 6 . All energies are in $\mathrm{kJ} / \mathrm{mol}$.

Inspection of the figure suggests that the inhibitor molecule adsorbs over the metal surface with a complete planar configuration. The adsorption energy in the present study is negative $(-111.01 \mathrm{~kJ} / \mathrm{mol})$, which reveals stronger adsorption of the inhibitor molecule. Thus, the result of MD is in good agreement with the quantum chemical calculations and experimental results.

\section{Mechanism of corrosion mitigation}

The adsorption of inhibitor molecule on the metal surface can be explained by the ideas obtained from the experimental in addition to quantum chemical study, and it could be taking place either physically or chemically or as a combination of both. Physical adsorption can be explained based on electrostatic interaction between the charged metal surface and the charged inhibitor molecules. Chemical adsorption occurs by donor-acceptor interactions between the lone pair electrons on the heteroatoms, $\pi$-electrons of multiple bonds as well as the phenyl group with the vacant d-orbitals of $\mathrm{Fe}^{61,62}$. Quantum chemical calculation shows that the inhibitor molecules exist in both neutral and protonated forms, so adsorption also occurs by a combination of both physical and chemical adsorption. In an acidic medium, the steel surface becomes positively charged after losing the electrons, as in Fig. 14. Thus, at the first stage, the $\mathrm{Cl}^{-}$ions become adsorbed on the steel surface. Then protonated inhibitor molecules become adsorbed through electrostatic interactions (physical adsorption). At the same time, lone pair of electrons on the heteroatoms, and the $\pi$-electrons of the benzene ring are donated to vacant $3 \mathrm{~d}$-orbitals of iron atoms (chemical adsorption). Additionally, the filled metal orbitals give the electrons to the LUMO of the inhibitor molecules through reterodonation ${ }^{63}$.

\section{Conclusions}

1. The $R_{p}$ values increase with the increase in the concentration of the inhibitor, thus increasing inhibition efficiency.

2. Potentiodynamic polarization measurements indicate that the inhibitor action is mixed type.

3. The adsorption of the inhibitor on the J55/N80 steel surface obey the Langmuir adsorption isotherm.

4. $\Delta G_{\text {ads }}^{\circ}$ results reveal that the adsorption of the inhibitors on the metal surface is spontaneous.

5. The AFM, SEM, XRD and contact angle analyses show that the inhibition of J55/N80 steel corrosion occurs due to the formation of an inhibitor film.

6. Quantum chemical study reveals that the neutral form of the inhibitor can donate the electrons to the metal, and the protonated form can accept electrons from the metal. Molecular dynamic simulation also corroborated the experimental results.

\section{References}

1. Bonis, M. R. \& Crolet, J. L. In, Corrosion, NACE International, Houston, TX, paper no. 466 (1989).

2. Heydari, M. \& Javidi, M. Corrosion inhibition and adsorption behaviour of an amido-imidazoline derivative on API $5 \mathrm{~L}$ X52 steel in CO2 saturated solution and synergistic effect of iodide ions. Corros. Sci. 61, 148-155 (2012).

3. López, D. A., Simison, S. N. \& De Sánchez, S. R. Inhibitors performance in $\mathrm{CO}_{2}$ corrosion: EIS studies on the interaction between their molecular structure and steel microstructure. Corros. Sci. 47, 735-755 (2005).

4. López, D. A., Schreiner, W. H., De Sánchez, S. R. \& Simison, S. N. The influence of carbon steel microstructure on corrosion layers: An XPS and SEM characterization. Appl. Surf. Sci. 207, 69-85 (2003).

5. Nesic, S. Uhlig's Corrosion Handbook, John Wiley \& Sons, Inc., Hoboken, New Jersey (2011).

6. Raja, P. B. \& Sethuraman, M. G. Natural products as corrosion inhibitor for metals in corrosive media- A review. Mater. Lett. 62, 113-116 (2008).

7. Lin, Y. et al. Effect of poly(methyl methacrylate-co-N-vinyl-2-pyrrolidone) polymer on 555 steel corrosion in $3.5 \% \mathrm{NaCl}$ solution saturated with CO2. J. Tai. Inst. Chem. Eng. 46, 214-222 (2015).

8. Singh, A. et al. Electrochemical, surface and quantum chemical studies of novel imidazole derivatives as corrosion inhibitors for J55 steel in sweet corrosive environment. J. Alloys Compd. 712, 121-133 (2017).

9. Singh, A. et al. Plant derived cationic dye as an effective corrosion inhibitor for 7075 aluminum alloy in $3.5 \% \mathrm{NaCl}$ solution. J. Ind . Eng. Chem. 20, 4276-4285 (2014)

10. Chitra, S., Parameswari, K. \& Selvaraj, A. Dianiline Schiff bases as inhibitors of mild steel corrosion in acid media. Int. J. Electrochem. Sci. 5, 1675-1697 (2010). 
11. Abd El-Lateef, H. M., Ismael, M. \& Mohamed, I. M. A. Novel Schiff base amino acid as corrosion inhibitors for carbon steel in $\mathrm{CO}_{2}{ }^{-}$ saturated 3.5\% $\mathrm{NaCl}$ solution: experimental and computational study. Corrosion Rev., https://doi.org/10.1515/corrrev-2014-0059 (2015)

12. Murad, K., Deeb, A. \& Kandil, F. Synthesis, Characterisation of some 2-azetidinone derivatives from 2,6-diaminopyridine and evaluation of their antimicrobial activity. Int. J. Chem.Tech. Res. 6, 3762-3766 (2014).

13. Singh, A. et al. Electrochemical and surface studies of some Porphines as corrosion inhibitor for J55 steel in sweet corrosion environment. Appl. Surf. Sci. 359, 331-339 (2015).

14. Singh, A., Lin, Y., Obot, I. B. \& Ebenso, E. E. Macrocyclic inhibitor for corrosion of $\mathrm{N} 80$ steel in $3.5 \% \mathrm{NaCl}$ solution saturated with $\mathrm{CO}_{2}$. J. Mol. Liq. 219, 865-874 (2016).

15. Frisch, M. J. et al. Gaussian 09, Revision C.01, Gaussian, Inc., Wallingford, CT (2009).

16. Dennington, R. D., Keith, T. A. \& Millam, C. M. GaussView 5.0 Wallingford, CT (2009).

17. Tian, H., Li, W., Cao, K. \& Hou, B. Potent inhibition of copper corrosion in neutral chloride media by novel non-toxic thiadiazole derivatives. Corros. Sci. 73, 281-291 (2013).

18. Hegazy, M. A., Badawi, A. M., Abd El Rehim, S. S. \& Kamel, W. M. Corrosion inhibition of carbon steel using novel N-(2-(2mercaptoacetoxy)ethyl)-N,N-dimethyl dodecan-1-aminium bromide during acid pickling. Corros. Sci. 69, 110-122 (2013).

19. Kovacevic, N. \& Kokalj, A. The relation between adsorption bonding and corrosion inhibition of azole molecules on copper. Corros. Sci. 73, 7-17 (2013).

20. Deng, S., Li, X. \& Xie, X. Hydroxymethyl urea and 1,3-bis(hydroxymethyl) urea as corrosion inhibitors for steel in $\mathrm{HCl}$ solution. Corros. Sci. 80, 276-289 (2014).

21. Abdullach, M. Rhodanine azosulpha drugs as corrosion inhibitors for corrosion of 304 stainless steel in hydrochloric acid solution. Corros. Sci. 44, 717-728 (2002).

22. Martinez, S. Inhibitory mechanism of mimosa tannin using molecular modeling and substitutional adsorption isotherms. Mater. Chem. Phys. 77, 97-102 (2003).

23. Cao, Z., Tang, Y., Cang, H., Xu, J., Lu, G. \& Jing, W. Novel benzimidazole derivatives as corrosion inhibitors of mild steel in the acidic media. Part II: Theoretical studies. Corros. Sci. 83, 292-298 (2014).

24. Frenkel, D. \& Smit, B. Understanding molecular simulation: From algorithms to applications. 2nd ed. San Diego: Academic Press; 2002.

25. Kirkpatrick, S., Gelatt, C. D. Jr \& Vecchi, M. P. Optimization by simulated annealing. Science. 220, 671-680 (1983).

26. Guo, L., Zhang, S. T., Lv, T. M. \& Feng, W. J. Comparative theoretical study on the corrosion inhibition properties of benzoxazole and benzothiazole. Res Chem Intermed 41, 3729-3742 (2015).

27. Sun, H. COMPASS: An ab Initio Force-Field Optimized for Condensed-Phase Applications Overview with Details on Alkane and Benzene Compounds. J Phys Chem B. 102, 7338-64 (1998).

28. Sánchez-Márquez, J. et al. Introducing "UCAFUKUI" software: reactivity-index calculations. J. Mol. Model. 20, 1-13 (2014).

29. Yang, W. \& Mortier, W. J. The use of global and local molecular parameters for the analysis of the gas-phase basicity of amines. J Am Chem Soc. 108, 5708-5711 (1986).

30. Daoud, D., Douadi, T., Issaadi, S. \& Chafaa, S. Adsorption and corrosion inhibition of new synthesized thiophene Schiff base on mild steel X52 in $\mathrm{HCl}$ and $\mathrm{H}_{2} \mathrm{O}$ 4 4 solutions. Corros. Sci. 79, 50-58 (2014).

31. Singh, A. et al. A study on the inhibition of $\mathrm{N} 80$ steel in $3.5 \% \mathrm{NaCl}$ solution saturated with $\mathrm{CO}_{2}$ by fruit extract of Gingko biloba. J. Tai. Inst. Chem. Eng. 45, 1918-1926 (2015).

32. Zhang, G., Chen, C., Lu, M., Chai, C. \& Wu, Y. Evaluation of inhibition efficiency of an imidazoline derivative in CO2_containing aqueous solution. Mater. Chem.Phys. 105, 331-340 (2007).

33. Singh, A. et al. Gingko biloba fruit extract as an eco-friendly corrosion inhibitor for 555 steel in $\mathrm{CO}_{2}$ saturated $3.5 \% \mathrm{NaCl}$ solution. J. Ind. Engg. Chem. 24, 219-228 (2015).

34. Singh, A. et al. Porphyrins as corrosion inhibitors for $\mathrm{N} 80$ Steel in $3.5 \% \mathrm{NaCl}$ solution: Electrochemical, quantum chemical, QSAR and Monte Carlo simulations studies. Molecules 20, 15122-15146 (2015).

35. Yadav, D. K., Chauhan, D. S., Ahamad, I. \& Quraishi, M. A. Electrochemical behavior of steel/acid interface: adsorption and inhibition effect of oligomeric aniline. RSC. Adv. 3, 632-646 (2013).

36. Singh, A., Singh, V. K. \& Quraish, M. A. Effect of fruit extracts of some environmentally benign green corrosion inhibitors on corrosion of mild steel in hydrochloric acid solution. J. Mater. Environ. Sci. 1, 162-174 (2010).

37. Qiang, Y. et al. Synergistic effect of tartaric acid with 2,6-diaminopyridine on the corrosion inhibition of mild steel in $0.5 \mathrm{M} \mathrm{HCl}$. Sci. Rep. 6, 33305, https://doi.org/10.1038/srep33305 (2016).

38. Yadav, D. K. \& Quraishi, M. A. Electrochemical investigation of Substituted Pyranopyrazoles Adsorption on Mild Steel in Acid Solution. Ind. Eng. Chem. Res. 51, 8194-8210 (2012).

39. Naderi, E., Jafari, A. H., Ehteshamzadeha, M. \& Hosseini, M. G. Effect of carbon steel microstructures and molecular structure of two new Schiff base compounds on inhibition performance in $1 \mathrm{M} \mathrm{HCl}$ solution by EIS. Mater. Chem. Phys. 115, 852-858 (2009).

40. Singh, A., Ebenso, E. E., Quraishi, M. A. \& Lin, Y. 5,10,15,20-Tetra(4-pyridyl)-21H,23H-porphine as an effective corrosion inhibitor for $\mathrm{N} 80$ steel in 3.5\% NaCl solution. Int. J. Electrochem. Sci. 9, 7495-7505 (2014).

41. Haque, J., Ansari, K. R., Srivastava, V., Quraishi, M. A. \& Obot, I. B. Pyrimidine derivatives as novel acidizing corrosion inhibitors for N80 steel useful for petroleum industry: A combined experimental and theoretical approach. J. Ind. Engg. Chem. 49, 176-188 (2017).

42. Ansari, K. R., Quraishi, M. A. \& Singh, A. Schiff's base of pyridyl substituted triazoles as new and effective corrosion inhibitors for mild steel in hydrochloric acid solution. Corros. Sci. 79, 5-15 (2014).

43. Khamis, A., Saleh, M. M. \& Awad, M. I. Synergistic inhibitor effect of cetylpyridinium chloride and other halides on the corrosion of mild steel in $0.5 \mathrm{M} \mathrm{H}_{2} \mathrm{SO}_{4}$. Corros. Sci. 66, 343-349 (2013).

44. Ismail, K. M. Electrochemical and quantum chemical study of purines as corrosion inhibitors for mild steel in $1 \mathrm{M} \mathrm{HCl}$ solution. Electrochim. Acta 53, 5953-5960 (2008).

45. Raja, P. B., Qureshi, A. K., Rahim, A. A., Osman, H. \& Awang, K. Neolamarckia cadamba alkaloids as eco-friendly corrosion inhibitors for mild steel in $1 \mathrm{M} \mathrm{HCl}$ media. Corros. Sci. 69, 292-301 (2013).

46. Bentiss, F. et al. Corrosion control of mild steel using 3,5-bis(4-methoxyphenyl)-4-amino-1,2,4-triazole in normal hydrochloric acid medium. Corros. Sci. 51, 1628-1635 (2009).

47. Yadav, M., Sinha, R. R., Sarkar, T. K. \& Tiwari, N. Corrosion inhibition effect of pyrazole derivatives on mild steel in hydrochloric acid solution. J. Adh. Sci. Tech. 29, 1690-1713 (2015).

48. Lin, Y. et al. Use of HPHT Autoclave to Determine Corrosion Inhibition by Berberine extract on Carbon Steels in $3.5 \% \mathrm{NaCl}$ Solution Saturated with $\mathrm{CO}_{2}$. Int. J. Electrochem. Sci. 10, 194-208 (2015).

49. Singh, A., Lin, Y., Zhu, C., Wu, Y. \& Ebenso, E. E. Use of HPHT autoclave to determine corrosion inhibition effect of poly(methyl methacrylate-co-N-vinyl-2-pyrrolidone) on carbon steels in $3.5 \% \mathrm{NaCl}$ solution saturated with $\mathrm{CO}_{2}$. Chin. J. Pol. Sci. 33, 339-348 (2015).

50. Singh, A. et al. Relevance of Electrochemical and Surface Studies to Probe Zanthoxylum schinifolium (sichuan pepper) as an Effective Corrosion Inhibitor for $\mathrm{N} 80$ steel in $\mathrm{CO}_{2}$ Saturated 3.5\% NaCl Solution. Int. J. Electrochem. Sci. 9, 5585-5595 (2014).

51. Liu, W. et al. 8-Hydroxyquinoline as an Effective Corrosion Inhibitor for 7075 Aluminium Alloy in $3.5 \% \mathrm{NaCl}$ Solution. Int. J. Electrochem. Sci. 9, 5574-5584 (2014). 
52. Quinn, B. M., Prieto, I., Haram, S. K. \& Bard, A. J. Electrochemical observation of a metal/insulator transition by scanning electrochemical microscopy. J. Phys. Chem. B. 105, 7474-7476 (2001).

53. Tsionsky, M., Bard, A. J., Dini, D. \& Decker, F. Polymer films on electrodes. 28. Scanning electrochemical microscopy study of electron transfer at poly(alkylterthiophene) films. Chem. Mater. 10, 2120-2126 (1998).

54. Maljuscha, A., Senozb, C., Rohwerderb, M. \& Schuhmanna, W. Combined high resolution Scanning Kelvin probe-Scanning electrochemical microscopy investigations for the visualization of local corrosion processes. Electrochim. Acta 82, 339-348 (2012).

55. Singh, A. et al. Corrosion mitigation of $\mathrm{J} 55 \mathrm{steel}$ in $3.5 \% \mathrm{NaCl}$ solution by a macrocyclic inhibitor. Appl. Surf. Sci. 356, 341-347 (2015).

56. Izquierdo, J., Nagy, L., Santana, J. J., Nagy, G. \& Souto, R. M. A novel microelectrochemical strategy for the study of corrosion inhibitors employing the scanning vibrating electrode technique and dual potentiometric/amperometric operation in scanning electrochemical microscopy: Application to the study of the cathodic inhibition by benzotriazole of the galvanic corrosion of copper coupled to iron. Electrochim. Acta 58, 707-716 (2011).

57. Aouinaa, N. et al. Initiation and growth of a single pit on 316L stainless steel: Influence of $\mathrm{SO}_{4}{ }^{2-}$ and $\mathrm{ClO}^{4-}$ anions. Electrochim. Acta 104, 274-281 (2013).

58. Chaubey, N., Singh, V. K. \& Quraishi, M. A. Effect of some peel extracts on the corrosion behavior of aluminum alloy in alkaline medium. Int. J. Ind. Chem. 6, 317-328 (2015).

59. Fukui, K. The role of frontier orbitals in chemical reactions. Physiology Or Medicine Literature Peace Economic Sciences 9 (1992).

60. Fu, J. J. et al. Experimental and theoretical study on the inhibition performances of quinoxaline and its derivatives for the corrosion of mild steel in hydrochloric acid. Ind. Eng. Chem. Res. 51, 6377-6386 (2012).

61. Ansari, K. R., Quraishi, M. A. \& Singh, A. Pyridine derivatives as corrosion inhibitors for N80 steel in 15\% HCl: Electrochemical, surface and quantum chemical studies. Measurement 76, 136-147 (2015)

62. Ansari, K. R. \& Quraishi, M. A. Corrosion inhibition of mild steel in hydrochloric acid by some pyridine derivatives: An experimental and quantum chemical study. J. Ind. Eng. Chem. 20, 2819-2829 (2014).

63. Ansari, K. R. \& Quraishi, M. A. Experimental and computational studies of naphthyridine derivatives as corrosion inhibitor for N80 steelin15\% hydrochloric acid. Physica E 69, 322-331 (2015).

\section{Acknowledgements}

The authors are thankful for the financial assistance provided by the National Natural Science Foundation of China (No. 51274170). The authors are also thankful to Dr. Ime B. Obot for his assistance.

\section{Author Contributions}

Ambrish Singh, Xihua Xu, Zhipeng Sun, and Yuanhua Lin, carried out all the experiments. K.R. Ansari carried out the quantum chemical calculations. Ambrish Singh, Yuanhua Lin and Ashok Kumar assisted in designing the work and write-up of the paper. All the authors have collectively contributed to the entire manuscript and have agreed to its publication.

\section{Additional Information}

Supplementary information accompanies this paper at https://doi.org/10.1038/s41598-017-13877-0.

Competing Interests: The authors declare that they have no competing interests.

Publisher's note: Springer Nature remains neutral with regard to jurisdictional claims in published maps and institutional affiliations.

(c) (i) Open Access This article is licensed under a Creative Commons Attribution 4.0 International

License, which permits use, sharing, adaptation, distribution and reproduction in any medium or format, as long as you give appropriate credit to the original author(s) and the source, provide a link to the Creative Commons license, and indicate if changes were made. The images or other third party material in this article are included in the article's Creative Commons license, unless indicated otherwise in a credit line to the material. If material is not included in the article's Creative Commons license and your intended use is not permitted by statutory regulation or exceeds the permitted use, you will need to obtain permission directly from the copyright holder. To view a copy of this license, visit http://creativecommons.org/licenses/by/4.0/.

(C) The Author(s) 2017 